\title{
Desvendando a relação entre corrupção e participação política na América Latina: diagnóstico e impactos da exposição a atos corruptos sobre a participação política
}

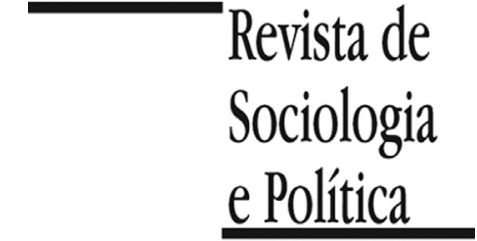

DOI $10.1590 / 1678-987317256302$

\author{
Robert Bonifácio e Mario Fuks
}

\begin{abstract}
Resumo
Investigamos a relação entre corrupção e participação política na América Latina a partir da seleção de três blocos de países que se situam em baixa, intermediária e alta posições no ranking de experiência com corrupção: Chile e Uruguai, Costa Rica e Nicarágua e México e Peru. O nível de análise é individual e a fonte de dados são três rodadas de pesquisas do Barômetro das Américas: 2006 (2008) e 2010. Dentre os principais resultados, destacam-se: (1) a identificação de quatro modalidades de participação política; (2) a existência de um padrão de associação positivo entre a exposição à corrupção e engajamento em atividades participativas, sem distinção entre os três blocos de países; (3) a maior tolerância à corrupção dentre os indivíduos que possuem experiência com corrupção, independentemente dessa característica ser complementada por ativismo político.
\end{abstract}

PALAVRAS-CHAVE: Corrupção; Participação Política; Permissividade à Corrupção; América Latina; Barômetro das Américas.

Recebido em 17 de Fevereiro de 2016. Aceito em 21 de Julho de 2016.

\section{Introdução ${ }^{1}$}

\author{
${ }^{1}$ Agradecemos aos \\ comentários e sugestões dos \\ pareceristas anônimos da \\ Revista de Sociologia e \\ Política.
}

\footnotetext{
${ }^{2}$ Agradecemos ao Latin American Public Opinion Project (LAPOP) e aos seus
}

\begin{abstract}
A despeito do grande interesse dos cientistas políticos por temas relacionados à corrupção e à participação política, a produção sobre a possível relação entre ambos os fenômenos é escassa. O presente artigo busca cobrir essa lacuna no contexto latino-americano. Dentre as principais contribuições, criamos uma tipologia de participação política com quatro modalidades específicas: (1) contato direto com atores políticos e governamentais; (2) ativismo comunitário; (3) ativismo partidário e eleitoral e (4) ativismo de protesto. A partir disso, investigamos a relação entre um indicador de corrupção - a experiência dos indivíduos com situações de pedido de propina por parte de policiais e funcionários públicos - e o engajamento nas diferentes modalidades de participação política. Além disso, qualificamos essa relação, analisando a tolerância à corrupção em função da experiência com corrupção e de ativismo político.
\end{abstract}

A investigação adota as perspectivas comparadas transversal (países) e longitudinal (anos) e tem o indivíduo como unidade de análise. O critério de seleção de casos é a variância da variável explicativa, ou seja, a posição dos países no ranking de experiência com corrupção. A partir disso, selecionamos três blocos de países, cujos indivíduos apresentam baixa, intermediária e alta experiência com corrupção: Chile e Uruguai, Costa Rica e Nicarágua e México e Peru, respectivamente. A fonte de dados é o Barômetro das Américas ${ }^{2}$, sendo utilizadas as pesquisas de opinião aplicadas em intervalos bienais entre os anos de 2006 e 2010. 
principais apoiadores (United States Agency for International Development, Inter-American Development Bank e Vanderbilt University) por disponibilizarem os dados.
No tópico a seguir, abordamos estudos sobre corrupção na área de comportamento político e construímos hipóteses. Na segunda seção, esclarecemos os aspectos metodológicos da pesquisa. Em seguida, definimos o conceito de participação política, selecionamos seus indicadores e criamos uma tipologia. A análise dos dados de testes estatísticos multivariados ocupa a seção final do artigo, seguida pelas considerações finais.

\section{Corrupção e comportamento político}

Nos estudos sobre o papel da corrupção no comportamento político, nota-se, de um lado, uma clara interpretação negativa sobre os efeitos da corrupção em atitudes políticas dotadas de civismo. A quase totalidade de estudos normativos e também de caráter empírico desenvolvidos após a terceira onda de democratização atestam essa condição. Por outro lado, a relação entre corrupção e participação política é ainda pouco explorada, com parcas considerações a respeito.

No campo normativo, os trabalhos de Hirschman (1983) e de Warren (2012) são referências e adotam a tese dos efeitos noviços da corrupção para o sistema político de uma forma geral.

Hirschman (1983) busca em aspectos sociopsicológicos a explicação para o envolvimento cíclico do indivíduo em atividades relacionadas às esferas pública (indivíduo identificado como "cidadão") e privada (indivíduo identificado como "consumidor"). A corrupção é importante para entender o desengajamento do cidadão em atividades da esfera pública relacionadas ao ativismo político. A percepção e a vivência com atos de corrupção ao longo do tempo potencializa a conformação e a consequente imersão do cidadão em atos corruptos. Tal movimento é compreendido pelo autor como um sintoma de mudança de preferência, com o indivíduo passando a priorizar interesses particulares via ganhos materiais advindos da corrupção. A persistente imersão em atos corruptos leva os indivíduos a pensarem que as atividades públicas são atividades vis por natureza e, assim, o que inicialmente era uma reação de descontentamento com a esfera pública torna-se um determinante de um descontentamento adicional e profundo que, por sua vez, prepara o terreno para mais corrupção. Ao final do processo, o espírito público é completamente eliminado. Nessas condições, a corrupção pode proporcionar ao "cidadão" uma rápida transição de volta ao seu papel de "consumidor".

Na perspectiva de Warren (2012), a corrupção mina os processos de natureza inclusiva da política, como a relação entre representantes e representados. A corrupção compromete o poder de voto e de fala dos indivíduos que almejam influenciar as decisões coletivas, removendo o poder e os recursos da arena pública para as relações parciais, particulares e privadas. Como consequência, tem-se o enfraquecimento da legitimidade democrática devido à exclusão de grande parte da população das decisões que a afetam. Ademais, a corrupção afeta a cultura democrática, destaca o autor. Se a corrupção se alastra, perde-se paulatinamente a confiança no processo de tomada de decisões públicas e, como consequência, é provável que os indivíduos se tornem cada vez mais cínicos a respeito do discurso público e da deliberação. A partir dessas considerações, Warren sugere que a corrupção possibilita a diminuição do horizonte das ações coletivas, encolhendo o domínio da democracia nesse campo.

Hirschman (1983) e Warren (2012) destacam que o envolvimento do indivíduo com as práticas corruptas tem consequências negativas tanto para o caráter democrático do sistema político quanto para as atitudes e comportamentos cívicos. Contudo, suas obras são essencialmente teóricas e normativas. 
Estudos mais recentes, para além de desenvolverem discussões teóricas, oferecem análises empíricas sobre o impacto da experiência com corrupção sobre as atitudes políticas, inclusive no contexto latino-americano.

Zéphyr (2008) e Seligson (2001; 2002) mostram a associação entre a exposição a corrupção e baixos patamares de adesão ao regime democrático. Utilizando dados do Barômetro das Américas de 2006, Zéphyr identifica que quanto maiores são os níveis de experiência com corrupção dos indivíduos, mais baixas são suas taxas de adesão à democracia. No primeiro trabalho de Seligson (2001), o autor utiliza dados de pesquisas de opinião de 1996 e 1998 aplicadas a nicaraguenses, a primeira antes e a segunda depois da realização de uma campanha nacional de conscientização contra a corrupção. Já no segundo trabalho (Seligson 2002), os dados são de pesquisas de opinião realizadas na Bolívia e Paraguai, em 1998, e El Salvador e Nicarágua, em 1999. Em ambos os estudos o autor encontra uma relação negativa entre experiência com corrupção e legitimidade democrática. No trabalho de 2002 também se investiga os efeitos da experiência com corrupção na confiança interpessoal, fenômeno entendido facilitador de formação de profundas e duráveis vínculos civis entre os indivíduos. Os efeitos negativos da corrupção mais uma vez se mostram presentes: quanto mais experiência com corrupção, menos confiança interpessoal.

Salinas e Booth (2011) investigam o impacto da exposição à corrupção sobre o civismo, sendo este medido por indicadores como a adesão ao regime democrático, o apoio ao direito de participação política e a tolerância em relação a formas contestatórias de participação política. Em todos os casos, os autores observaram associações negativas, concluindo que a corrupção é nociva ao civismo.

Para Bohn (2012), a legitimidade do regime democrático deriva do apoio em massa aos seus principais processos, tais como eleições livres e justas, liberdades e direitos institucionalizados e transparência e accountability nas instituições públicas. A manifestação da corrupção no ambiente democrático poderia viciar as interações entre indivíduo e estrutura, causando a diminuição de confiança e de satisfação dos indivíduos com princípios e instituições democráticas. A partir dessas considerações, a autora direciona a sua investigação, analisando o papel da experiência com corrupção na satisfação dos cidadãos com a democracia realmente existente, com base em dados do Barômetro das Américas de 2010. Os resultados apontam que, quanto maiores os níveis de experiência com corrupção, menor é a satisfação com a democracia.

Todos os autores abordados anteriormente esclarecem que a proximidade do indivíduo com a corrupção o torna menos suscetível a expressar atitudes políticas congruentes com os princípios democráticos. Como a participação política é a afirmação de um dos principais princípios democráticos, espera-se, aqui, a mesma relação: quanto mais corrupção, menos participação. Contudo, os escassos estudos sobre a relação entre corrupção e participação política trazem resultados ambivalentes.

Em Olsson (2014), investiga-se a relação entre percepção de corrupção no serviço público e três tipos de participação política (comparecimento eleitoral e participação política institucionalizada e não institucionalizada) em 33 países, usando os dados de 2003 a 2006 do International Social Survey Programme (ISSP). A autora observa que a associação negativa entre percepção de corrupção e participação política institucionalizada e não institucionalizada só se mostra presente em modelos univariados. Ou seja, não se observa qualquer padrão robusto de associação entre percepção de corrupção e atividades participativas não-eleitorais. Já para comparecimento eleitoral, observa-se uma clara tendência de associação negativa: quem percebe corrupção no serviço público tem menores níveis de presença em votações. 
${ }^{3}$ Cabe ressaltar que nossa definição de participação política e a posterior análise de dados das atividades participativas tem como referência a finalidade do fenômeno e não as motivações individuais que justificam a sua ocorrência.
Com desenho de pesquisa mais próximo ao desenvolvido neste trabalho, o artigo de Bonifácio e Paulino (2015) se atém à relação entre medidas de proximidade à corrupção e engajamento em atividades participativas nas Américas e no Caribe. Utilizando dados do Barômetro das Américas - rodadas de 2006, 2008, 2010 e 2012 - os autores mostram que indivíduos que vivenciaram situações de pedido de propina por parte de policiais e funcionários públicos apresentam maiores chances de engajamento em atividades participativas do que os indivíduos que não possuem tal experiência. Esse resultado é válido para quatro das cinco modalidades de participação política analisadas: ativismo comunitário, ativismo partidário e eleitoral, contato com atores políticos e governamentais e ativismo de protesto. Comparecimento eleitoral constitui-se uma exceção, sem padrão identificável.

Esses resultados desafiam a tese endossada por maior parte da literatura de comportamento político, que afirma a existência de associação negativa entre experiência com corrupção e atitudes políticas cívicas. Temos, portanto, visões contraditórias acerca dos possíveis efeitos da proximidade com a corrupção para as orientações políticas individuais.

Decidimos, no presente estudo, construir uma hipótese afinada com os resultados do trabalho de Bonifácio e Paulino (2015), por conta da proximidade de nosso desenho de pesquisa com aquele implementando pelos autores. Assim, a nossa hipótese é que os indivíduos que possuem experiência com corrupção têm mais chances de engajamento em atividades participativas (H1).

Embora seja importante considerar a existência de diversas motivações para a adesão a cada uma das modalidades de participação ${ }^{3}$, não vislumbramos diferenças no processo de engajamento político. Ademais, o padrão de associação entre os indicadores de corrupção e as modalidades de participação política presentes no estudo a partir do qual baseamos nossa hipótese é sempre positivo. Logo, não há justificativa para construirmos hipóteses para cada uma das modalidades de participação política.

Se, por um lado, não entendemos como necessária a construção de hipóteses para cada uma das modalidades de participação política, por outro lado, acreditamos haver variação entre os três blocos de países selecionados. A quantidade de experiência com corrupção é um dos "termômetros" que indica o quanto o fenômeno é alastrado numa sociedade. Em países em que a incidência de convivência com atos corruptos é alta, é de se esperar que a corrupção ocupe papel de destaque na dinâmica das relações sociais. Esperamos um efeito decrescente da corrupção na participação política entre esses três blocos de países, isto é, a relação será mais vigorosa de forma decrescente a partir dos contextos com maiores para os com menores níveis de experiência com corrupção: México e Peru $\rightarrow$ Costa Rica e Nicarágua $\rightarrow$ Chile e Uruguai.

Seguindo esse raciocínio e assumindo uma perspectiva comparada de análise, a nossa segunda hipótese é que os mexicanos e peruanos que possuem experiência com corrupção são os indivíduos que apresentam os maiores valores de razão de chance na ocorrência de participação $(\mathrm{H} 2)$, considerando todas as suas modalidades e todas as rodadas de dados, ao passo que os chilenos e uruguaios apresentam os menores desses valores (H3). Para o caso da Costa Rica e Nicarágua, esperamos que o cenário seja o do meio termo entre os dois anteriormente especificados (H4).

No caso de uma clara corroboração ou refutação da hipótese que versa sobre a relação positiva entre corrupção e participação política, uma pergunta se segue quase que naturalmente: seria essa relação robusta ou dotada de espuriedade? Tal suspeição é comumente direcionada a padrões de associação encontrados em estudos cujos objetivos ainda não são usuais na literatura especializada. Isso 
se aplica a este trabalho. Como forma de verificar o quanto que uma possível relação entre corrupção e participação política é sólida, acrescentamos aos modelos de regressão duas variáveis que os especialistas atestam ser de essencial importância para explicar ativismo político: escolaridade e interesse por política

\section{Variáveis concorrentes: escolaridade e interesse por política}

Talvez nenhuma outra variável seja tão relevante para o comportamento político quanto a escolaridade, chamada de "solvente universal" nesse campo de estudos (Converse 1972).No que se refere a participação política, a escolaridade é compreendida como um forte preditor de ativismo político. Um exemplo da centralidade da escolaridade na moldagem do comportamento político é o modelo do voluntarismo cívico, proposto por Verba, Nie e Kim (1987; 1995). Em seus estudos, tanto os comparativos como os atrelados apenas ao contexto estadunidense, os autores arrolam a escolaridade entre os recursos que potencializam o engajamento em atividades participativas de diversas naturezas.

Juntamente com a escolaridade, o interesse por política é tratado como um dos componentes do conceito de sofisticação política (Neuman 1986). A ideia geral é que aqueles que possuem interesse por política compreendem e relacionam de forma mais coesa fatos e abstrações ligados ao mundo da política. Também há um componente comportamental, na medida em que o interesse por política funcionaria como uma mola que impulsiona o ativismo político. Ou seja, independentemente do nível de recursos, o indivíduo que possui interesse por política será relativamente mais ativo politicamente que os seus pares (Verba, Nie \& Kim 1987).

Em suma, o que objetivamos com a adição de variáveis sobre escolaridade e sobre interesse por política é testar a possível robustez de uma relação entre experiência com corrupção e participação política.

\section{Permissividade à corrupção}

Embora seja necessário diagnosticar um possível padrão de associação entre corrupção e participação política nos contextos selecionados, isso não é suficiente para o entendimento da relação. Também é essencial extrair algum significado dessa relação e qualificá-la. Especificamente, buscamos entender se a proximidade de atos corruptos e o consequente ativismo político estão associados à rejeição ou à tolerância com a corrupção. Ou seja, buscamos identificar se predomina a indignação ou a resignação entre esses perfis sociais.

A ideia de permissividade à corrupção remete a diversas atitudes favoráveis ou, pelo menos, não contrárias à manifestação de atos corruptos na sociedade. Como exemplo, podemos citar a ideia do "rouba, mas faz", a aceitação da compra de votos, a aprovação da manifestação cotidiana de pequenas corrupções, a tolerância ao pagamento de propina, entre outros. Todas essas questões são abarcadas pelo Barômetro das Américas ao longo dos anos, nas dezenas de países cobertos por sua amostra. No entanto, apenas a última questão - tolerância ao pagamento de propina - é aplicada em todas as rodadas e países, permitindo assim uma adequada comparação.

Para a formulação de hipótese, baseamo-nos em resultados de estudos sobre os efeitos da corrupção em atitudes políticas. Desse modo, a nossa hipótese é que o indivíduo cujo perfil se caracteriza pela combinação entre experiência com corrupção e engajamento em atividades participativas é o que apresenta a maior propensão de tolerância ao pagamento de propina (H5). Ademais, 


\section{Aspectos metodológicos}

testamos a hipótese de que a intensidade de tolerância à corrupção desse perfil nos países seguirá a ordem decrescente do ranking de experiência com corrupção. Ou seja, será maior no México e Peru, seguido por Costa Rica e Nicarágua e por Chile e Uruguai, sucessivamente (H6).

${ }^{4} \mathrm{Em}$ caso de interesse em replicação e/ou checagem dos testes, a sintaxe (comandos de testes estatísticos) pode ser obtida via contato com os autores.

\footnotetext{
${ }^{5}$ Os códigos das variáveis nos questionários do Barômetro
}

A fonte de dados para as nossas análises é o Barômetro das Américas. Trata-se de um conjunto de pesquisas de opinião aplicadas em indivíduos de dezenas de países das Américas e do Caribe, realizado pelo Latin American Public Opinion Project (LAPOP), da Vanderbilt University. Alguns motivos levaram a essa escolha: a existência de dezenas de questões sobre participação política, a medição da experiência dos indivíduos com situações de pedido de propina, a disponibilidade de dados ao longo do tempo em intervalos bienais e existência de amostras representativas para a população de cada país.

Cabe ressaltar, porém, que o tamanho das amostras varia de acordo com o país e, por isso, ponderamos todos os testes estatísticos realizados no trabalho pela variável de peso chamada weight1500.

São realizados testes estatísticos de natureza descritiva e inferencial. Por questão de espaço, ao longo do texto selecionamos resultados apenas de uma rodada, para cada teste estatístico realizado. O conjunto de informações complementares encontram-se no Apêndice $\mathrm{A}^{4}$.

No tópico seguinte, utilizamos o teste de análise fatorial exploratória com a matriz de correção policórica, o mais adequado para os tipos de variáveis envolvidas nas análises, binária e categórica (Gorsuch 1983; Drasgow 1988). Esse teste é aplicado para a construção de uma tipologia de participação política. Os fatores gerados justificam a criação de índices para quatro modalidades de participação.

A partir da identificação de quatro tipos de participação política, construímos os índices correspondentes. Todas as categorias que indicam participação foram agregadas e receberam o valor " 1 ", ao passo que as categorias que indicam não participação receberam valor "0". Tal decisão se baseia na distribuição de frequência das categorias de participação, percentualmente muito inferiores às categorias de não participação. Transformando os valores dos índices de participação em binários, conseguimos a distribuição de frequência mais equilibrada possível entre participação e não participação.

Devido à natureza binária dos índices de participação política, utilizamos o teste de regressão logística binária. Foram construídos dois modelos para cada modalidade de participação política. O modelo inicial tem como preditor apenas a variável de experiência com corrupção e o modelo completo adiciona as variáveis de controle (sexo, idade e renda) e as variáveis explicativas concorrentes (escolaridade e interesse por política). Para a leitura dos dados, transformamos os valores de exponencial de beta em efeitos percentuais a partir da seguinte fórmula: $[\operatorname{Exp}(\mathrm{B})-1] * 100$.

A experiência com situações de pedido de propina é o indicador de corrupção selecionado. A escolha se baseia no artigo de Bonifácio e Paulino (2015), que identificam nessa medida de corrupção aquela que melhor discrimina comportamento participativo e não participativo entre os indivíduos de países das Américas e do Caribe. São duas as variáveis relacionadas, que apontam experiência individual com situações de pedido de propina por parte de policiais e de funcionários públicos ${ }^{5}$. Criamos a variável explicativa a partir da soma dessas duas variáveis e da agregação dos valores iguais ou maiores que 1 . 
das Américas são, respectivamente, EXC2 e EXC6. A categoria de resposta "sim" indica experiência com corrupção.
Utilizamos a variável sobre tolerância à propina para tratarmos da permissividade à corrupção. As análises advêm de resultados de testes de valores preditos, que indicam a probabilidade de permissividade para quatro tipos diferentes de perfis, criados a partir de interações entre as categorias de evento e não evento de experiência com corrupção e participação política. São eles: (1) experiente com corrupção + ativista político, (2) experiente com corrupção + não ativista político; (3) inexperiente com corrupção + ativista político; (4) inexperiente com corrupção + não ativista político.

O critério de seleção de casos foi a frequência de experiência com corrupção. Chile e Uruguai, Costa Rica e Nicarágua e México e Peru são blocos de países que possuem, respectivamente, os indivíduos com mais baixas, moderadas e mais altas taxas de experiência com corrupção ao longo dos anos selecionados. Com isso, segue-se a ideia de King, Keohane e Verba (1994), que afirmam que o critério fundamental para se evitar o problema do viés de seleção é basear a escolha dos casos a partir da variância da variável explicativa. A escolha por blocos de países evita possíveis problemas em testes estatísticos inferenciais por conta do baixo número de casos. Essa situação poderia ocorrer caso houvesse a seleção de apenas um país para cada nível de experiência com corrupção.

Por fim, ressaltamos um problema no tratamento dos dados. $\mathrm{O}$ primeiro se trata da baixa aplicação da pergunta sobre a participação em protestos entre os países presentes na amostra de 2008 do Barômetro das Américas. Essa questão está disponível para apenas 8 do total de 24 países, sendo que, dos países selecionados para este trabalho, apenas na Costa Rica e no México essa variável está disponível. Considerando o caráter comparativo de nosso estudo, excluímos essa variável para essa rodada.

\section{Participação política: definição, indicadores e tipologia}

${ }^{6}$ A codificação e as categorias que indicam participação estão presentes nos questionários do Barômetro das Américas da seguinte forma,
Antes de procedermos à análise da relação entre corrupção e participação política, faz-se imperativo tecer considerações sobre o último fenômeno. É consenso atribuir à participação política a característica polissêmica, algo que passou a ser encarado como um problema a partir do momento em que os estudos na área começaram a se despir de normatividade.

O debate teórico sobre o fenômeno é extenso e os estudos de Brady (1999) e Borba (2012) fazem uma síntese das principais contribuições e controvérsias. Há, por exemplo, diferentes visões acerca do ambiente em que o fenômeno se desenvolve e a sua dimensionalidade, além do repertório das atividades participativas. Um único ponto parece ser consensual: a consideração de que a participação é um comportamento, uma ação, e não uma atitude, que é algo imbuído de caráter subjetivo. Em adição a essa questão, entendemos que participar significa tomar parte em algo (Fialho 2008) e que o fenômeno pode se desenvolver em diversas arenas, com os atores envolvidos buscando influir na distribuição de poder de forma conflitiva ou cooperativa (Reis 2000).

Com base nas considerações acima, definimos participação política como atividades exercidas por cidadãos, em diversas arenas, que objetivam influenciar as dinâmicas de poder.

A partir da definição, podemos arrolar como indicadores de participação política dezenas de atividades, mas as limitações da base de dados do Barômetro das Américas só tornam possível trabalharmos com 10 delas (Quadro 1) ${ }^{6}$.

$\mathrm{O}$ voto certamente é um indicador de participação política. Contudo, não o incluímos neste trabalho porque, como já alertavam Verba, Nie e Kim (1987), essa atividade participativa difere substancialmente das demais, sendo preciso 
respectivamente: $\mathrm{PP} 2, \mathrm{CP} 2$, CP4a e CP4 ("sim"); CP5 (em 2006, "sim"; em 2008 e 2010, "uma vez por semana", "uma ou duas vezes por mês" e "uma ou duas vezes por ano"); CP8 e CP13 ("uma vez por semana", "uma ou duas vezes por mês" e "uma ou duas vezes por ano"); PP1

("frequentemente", "de vez em quando" e "muito raramente"); PROT1 (2006 e 2008, "algumas vezes" e "quase nunca”); PROT3 (2010, "sim"). reflexões teóricas e aproximações empíricas específicas. Bonifácio e Paulino (2015), por exemplo, identificaram que os fatores explicativos do comparecimento eleitoral se relacionam de forma substancialmente diferente dos demais indicadores de participação política.

A participação política pode ser abordada como um fenômeno de natureza unidimensional ou multidimensional. Para lidar empiricamente com essa questão, utilizamos a análise fatorial exploratória (Quadro 2 e Tabela 1). Os resultados mostram-se uniformes em todas as rodadas, com poucas exceções. Em todas os blocos de países nas três primeiras rodadas, é perceptível a identificação, num primeiro momento, de três modalidades de participação política: (1) contato com atores políticos e governamentais, (2) ativismo comunitário e (3) ativismo partidário e eleitoral.

As variáveis referentes à modalidade de contato com atores políticos e governamentais expressam contato direto entre representante(s) e represen-

Quadro 1 - Indicadores de participação política selecionados

\begin{tabular}{ll}
\hline & Indicador \\
\hline 1 & Trabalhar em campanha eleitoral \\
2 & Contatar deputados (estaduais e federais) \\
3 & Contatar atores políticos governamentais (ministérios e secretarias) \\
4 & Contatar atores políticos locais (prefeitos e autoridades militares) \\
5 & Contatar vereadores e atores governamentais locais \\
6 & Agir para solução de problemas na comunidade em que se vive \\
7 & Assistir a reuniões de associação de bairro \\
8 & Assistir a reuniões de partido político \\
9 & Tentar convencer outros sobre a escolha do voto \\
10 & Participar de manifestações ou protestos públicos \\
\hline
\end{tabular}

Fonte: Os autores.

Quadro 2 - Modalidades de participação política

\begin{tabular}{ll}
\hline Modalidades & Variáveis constituidoras \\
\hline $\begin{array}{l}\text { Contato com atores políticos e } \\
\text { governamentais }\end{array}$ & Contato com deputado estadual ou federal \\
& $\begin{array}{l}\text { Contato com atores governamentais } \\
\text { Contato com atores políticos locais } \\
\text { Contato com vereadores e/ou atores } \\
\text { governamentais locais }\end{array}$ \\
\hline Ativismo comunitário & $\begin{array}{l}\text { Ação em prol da comunidade } \\
\text { Assistir reunião de associação de bairro }\end{array}$ \\
\hline Ativismo partidário e eleitoral & $\begin{array}{l}\text { Assistir a reunião de partidos políticos ou } \\
\text { movimento político }\end{array}$ \\
& $\begin{array}{l}\text { Trabalho em campanha eleitoral } \\
\text { Convencer os outros sobre a escolha do voto }\end{array}$ \\
\hline Ativismo de protesto & Participar de protestos e manifestações \\
\hline
\end{tabular}

Fonte: Os autores. 
Tabela 1 - Análise fatorial exploratória com os indicadores de participação política (2010)

\begin{tabular}{|c|c|c|c|c|c|c|c|c|c|}
\hline & \multicolumn{3}{|c|}{ Chile e Uruguai } & \multicolumn{3}{|c|}{$\begin{array}{c}\text { Costa Rica e } \\
\text { Nicarágua }\end{array}$} & \multicolumn{3}{|c|}{ México e Peru } \\
\hline & 1 & 2 & 3 & 1 & 2 & 3 & 1 & 2 & 3 \\
\hline Contato: Deputado estadual e federal & & 0,672 & & 0,802 & & & 0,751 & & \\
\hline Contato: Atores políticos governamentais & & 0,677 & & 0,725 & & & 0,748 & & \\
\hline Contato: Atores políticos locais & & 0,834 & & 0,836 & & & 0,850 & & \\
\hline Contato: Vereador & & 0,678 & & 0,790 & & & 0,685 & & \\
\hline Ação em prol da comunidade & & & 0,526 & & & 0,492 & & & 0.559 \\
\hline Assistir reunião de associação de bairro & & & 0,555 & & & 0,570 & & & 0.582 \\
\hline Assistir reunião de partido político & 0.893 & & & & 0,585 & & & 0,594 & \\
\hline Trabalho em campanha eleitoral & 0.852 & & & & 0,616 & & & 0,654 & \\
\hline Convencimento sobre escolha de voto & 0.580 & & & & 0,438 & & & 0,507 & \\
\hline Participar de protestos & 0.582 & & & & 0,489 & & & 0,433 & \\
\hline Alpha de Cronbach & & 0,570 & & & 0,602 & & & 0,609 & \\
\hline$K M O$ & & 0,745 & & & 0,798 & & & 0,825 & \\
\hline
\end{tabular}

Fonte: Os autores, a partir de Latin American Public Opinion Project (2010).

${ }^{7}$ Ambos os estudos focam o contexto latino-americano, contudo, há pequenas diferenças em relação às variáveis e ao período temporal selecionados e às técnicas empregadas. tado(s), sem a presença de manifestações ou atos contestatórios, ou seja, de atividades que objetivam exercer pressão pública nas autoridades. Já a modalidade de ativismo comunitário denota atuação em questões políticas de abrangência exclusivamente local, visando influenciar políticas e atores que cuidam de problemas da comunidade em que se vive. As variáveis da modalidade de ativismo partidário e eleitoral, por sua vez, abarcam atividades que têm como horizonte a influência em processos eleitorais e que estão atreladas a instituições e eventos oficiais, como os partidos políticos e as eleições.

O ativismo de protesto, contudo, não compõe nenhuma das dimensões elencadas, uma vez que o coeficiente da variável que expressa participação em manifestações e protestos é baixo em todos os fatores. Por isso, ele constitui uma dimensão específica da participação política.

Os resultados são semelhantes aos encontrados por Bonifácio e Paulino (2015) e por Booth e Seligson (2009) ${ }^{7}$. Cabe ressaltar, porém, que a multidimensionalidade da participação política não é algo distintivo das Américas e do Caribe, uma vez que estudos de Verba, Nie e Kim (1987), Norris (2002) e Teorell, Torcal e Montero (2007), que contêm dados referentes a outros anos e a indivíduos de países de outras regiões do mundo, também identificaram a mesmo fenômeno. Esses achados contribuem para descartarmos a consideração de que o fenômeno da participação política tem natureza una, conforme sugeria Milbrath (1965), e asseverar a sua condição multidimensional. Logo, a participação política deve ser compreendida a partir de repertórios segmentados, desenvolvidos em diferentes arenas e com alvos diferenciados.

\section{Corrupção e Participação Política: análise dos dados}

\section{VII.1. A natureza da relação entre corrupção e participação política}

A partir dos resultados apresentados nas Tabelas 2, 3, 4 e 5, constatamos uma clara relação positiva entre experiência com corrupção e cada uma das quatro modalidades de participação política, nos três blocos de países analisados. Ou seja, os indivíduos que possuem experiência com corrupção têm 
mais chances de se engajarem em atividades participativas do que os indivíduos que não possuem experiência com corrupção. Não há sequer uma exceção a respeito da direção dessa associação em cada uma das quatro modalidades: na totalidade dos casos, o efeito percentual é sempre positivo, seja no modelo inicial, seja no modelo completo.

Destacamos, como exemplo, que os chilenos e uruguaios que possuem experiência com atos corruptos apresentam cerca de $123 \%$ mais chances de entrar em contato com atores políticos e governamentais do que os que não possuem experiência com atos corruptos, ao passo que esses valores atingem $24,5 \%$ para costa-riquenhos e nicaraguenses e $37,8 \%$ para mexicanos e perua-

Tabela 2 - Preditores de contato com atores políticos e governamentais (2010)

\begin{tabular}{|c|c|c|c|c|c|c|}
\hline & \multicolumn{2}{|c|}{ Chile e Uruguai } & \multicolumn{2}{|c|}{ Costa Rica e Nicarágua } & \multicolumn{2}{|c|}{ México e Peru } \\
\hline & 1 & 2 & 1 & 2 & 1 & 2 \\
\hline Experiência com corrupção & 74,5 & $122,7 * * *$ & 21,1 & 24,5 & $34,9 * * *$ & $37,8 * * *$ \\
\hline Interesse por política & & $35,9 * * *$ & & $32,1 * * *$ & & $39,2 * * *$ \\
\hline Escolaridade- Superior & & 14,8 & & 0,9 & & $29,2 * *$ \\
\hline Sexo masculino & & $-38,0 * * *$ & & $-7,0$ & & 6,2 \\
\hline Idade & & 0,3 & & $1,2 * * *$ & & $1,2 * * *$ \\
\hline Renda familiar & & $-7,7 * * *$ & & $-5,6^{* *}$ & & $-5,8 * * *$ \\
\hline Constante & $-64,0 * * *$ & $-53,3 * * *$ & $-63,0 * * *$ & $-81,0 * * *$ & $-66,3 * * *$ & $-80,0 * * *$ \\
\hline Qui quadrado & $8,3 * * *$ & $67,3 * * *$ & 1,4 & $26,2 * * *$ & $10,0 * * *$ & $48,6 * * *$ \\
\hline R2 Nagelkerke & 0,004 & 0,036 & 0,001 & 0,016 & 0,005 & 0,027 \\
\hline$\%$ de acerto & 72,9 & 72,5 & 78,1 & 77,5 & 73,5 & 73,1 \\
\hline Log da pseudo-verossimilhança & 3462,8 & 3072,8 & 3069,5 & 2627,1 & 3396,2 & 3026,4 \\
\hline
\end{tabular}

Fonte: Os autores, a partir de Latin American Public Opinion Project (2010).

$*=\mathrm{p}$ valor menor/igual a 0,$10 ; * *=\mathrm{p}$ valor menor ou igual a 0,$05 ; * *=\mathrm{p}$ valor menor ou igual a 0,01 .

Tabela 3 - Preditores de ativismo comunitário (2010)

\begin{tabular}{|c|c|c|c|c|c|c|}
\hline & \multicolumn{2}{|c|}{ Chile e Uruguai } & \multicolumn{2}{|c|}{ Costa Rica e Nicarágua } & \multicolumn{2}{|c|}{ México e Peru } \\
\hline & 1 & 2 & 1 & 2 & 1 & 2 \\
\hline Experiência com corrupção & 21,4 & 38,5 & 20,4 & 23,4 & $21,9 * *$ & $21,9 * *$ \\
\hline Interesse por política & & $29,0 * *$ & & $58,2 * * *$ & & $33,7 * * *$ \\
\hline Escolaridade- Superior & & 5,3 & & $27,8^{*}$ & & $31,6^{* * *}$ \\
\hline Sexo masculino & & $-8,7$ & & $21,2 * *$ & & 0,7 \\
\hline Idade & & $0,8 * * *$ & & $1,4 * * *$ & & $1,7 * * *$ \\
\hline Renda familiar & & $-3,3$ & & $-1,2$ & & $-0,5$ \\
\hline Constante & $-70,0 * * *$ & $-77,0 * * *$ & $-55,0 * * *$ & $-80,5 * * *$ & $-27,0 * * *$ & $-70,0 * * *$ \\
\hline Qui quadrado & 0,7 & $15,9 * *$ & 1,4 & $51,2 * * *$ & 4,2 & $57,0 * * *$ \\
\hline R2 Nagelkerke & 0,000 & 0,010 & 0,001 & 0,032 & 0,002 & 0,033 \\
\hline$\%$ de acerto & 76,9 & 75,9 & 68,6 & 67,1 & 56,8 & 57,3 \\
\hline Log da pseudo-verossimilhança & 2764,7 & 2504,3 & 3188,2 & 2754,4 & 3514,4 & 3102,0 \\
\hline
\end{tabular}

Fonte: Os autores, a partir de Latin American Public Opinion Project (2010).

$*=\mathrm{p}$ valor menor/igual a 0,$10 ; * *=\mathrm{p}$ valor menor ou igual a 0,$05 ; * * *=\mathrm{p}$ valor menor ou igual a 0,01 . 
Tabela 4 - Preditores de ativismo partidário e eleitoral (2010)

\begin{tabular}{|c|c|c|c|c|c|c|}
\hline & \multicolumn{2}{|c|}{ Chile e Uruguai } & \multicolumn{2}{|c|}{ Costa Rica e Nicarágua } & \multicolumn{2}{|c|}{ México e Peru } \\
\hline & 1 & 2 & 1 & 2 & 1 & 2 \\
\hline Experiência com corrupção & $71,0 * * *$ & $40,0 *$ & $81,6 * * *$ & $58,4 * * *$ & $27,9 * * *$ & $20,9 * *$ \\
\hline Interesse por política & & $142,2 * * *$ & & $181,2 * * *$ & & $65,4 * * *$ \\
\hline Escolaridade- Superior & & $20,8 *$ & & $62,9 * * *$ & & $35,9 * * *$ \\
\hline Sexo masculino & & 1,6 & & $35,1 * * *$ & & 14,9 \\
\hline Idade & & $-1,2$ & & $0,9 * * *$ & & $0,6^{* *}$ \\
\hline Renda familiar & & $7,5 * * *$ & & 0,7 & & 2,2 \\
\hline Constante & $-47,6 * * *$ & $-84,0 * * *$ & $-52,2 * * *$ & $-88,0 * * *$ & $-46,0 * * *$ & $-76,3 * * *$ \\
\hline Qui quadrado & $8,4 * * *$ & $247,5 * * *$ & $18,6 * * *$ & $170,0 * * *$ & $7,9 * * *$ & $69,1 * * *$ \\
\hline R2 Nagelkerke & 0,04 & 0,123 & 0,009 & 0,091 & 0,004 & 0,035 \\
\hline$\%$ de acerto & 65,1 & 66,3 & 66,5 & 67,5 & 63,6 & 63,2 \\
\hline Log da pseudo-verossimilhança & 3803,7 & 3178,5 & 3706,9 & 3024,9 & 3842,0 & 3401,0 \\
\hline
\end{tabular}

Fonte: Os autores, a partir de Latin American Public Opinion Project (2010).

$*=$ p valor menor/igual a 0,$10 ; * *=$ p valor menor ou igual a 0,$05 ; * * *=$ p valor menor ou igual a 0,01 .

Tabela 5 - Preditores de ativismo de protesto (2010)

\begin{tabular}{|c|c|c|c|c|c|c|}
\hline & \multicolumn{2}{|c|}{ Chile e Uruguai } & \multicolumn{2}{|c|}{ Costa Rica e Nicarágua } & \multicolumn{2}{|c|}{ México e Peru } \\
\hline & 1 & 2 & 1 & 2 & 1 & 2 \\
\hline Experiência com corrupção & $59,7 *$ & 22,1 & $137,6 * * *$ & $76,7 * * *$ & $27,9 * * *$ & $20,9 * *$ \\
\hline Interesse por política & & $647,5 * * *$ & & $146,0 * * *$ & & $65,4 * * *$ \\
\hline Escolaridade- Superior & & 27,6 & & $101,7 * * *$ & & $35,9 * * *$ \\
\hline Sexo masculino & & $-10,7$ & & $60,0 * * *$ & & 14,9 \\
\hline Idade & & $-0,4$ & & $-1,0$ & & $0,6^{* *}$ \\
\hline Renda familiar & & $15,4 * * *$ & & $9,5^{* *}$ & & 2,2 \\
\hline Constante & $-92,0 * * *$ & $-91,0 * * *$ & $-92,4 * * *$ & $-97,5 * * *$ & $-47,0 * * *$ & $-77,0 * * *$ \\
\hline Qui quadrado & 2,4 & $154,0 * * *$ & $17,0 * * *$ & $90,4 * * *$ & $7,9 * * *$ & $69,1 * * *$ \\
\hline R2 Nagelkerke & 0,002 & 0,129 & 0,014 & 0,082 & 0,004 & 0,035 \\
\hline$\%$ de acerto & 91,9 & 91,7 & 92,3 & 92,0 & 63,6 & 63,2 \\
\hline Log da pseudo-verossimilhança & 1664,0 & 1368,7 & 1591,1 & 1314,5 & 3842,0 & 3401,0 \\
\hline
\end{tabular}

Fonte: Os autores, a partir de Latin American Public Opinion Project (2010).

$*$ = p valor menor/igual a 0,$10 ; * *=$ p valor menor ou igual a 0,$05 ; * * *=$ p valor menor ou igual a 0,01 .

nos. Esses resultados são observados considerando os efeitos conjuntos das variáveis de controle e as variáveis explicativas concorrentes.

Em suma, observamos um padrão de associação positivo entre experiência com corrupção e ativismo político, que se sustenta em comparações transversais - ou seja, nos blocos de países e longitudinais - ao longo do período temporal para todas as quatro modalidades de participação. Ademais, esse padrão de associação mostra-se, em boa parte dos casos, estatisticamente significante. Com base em todos esses resultados, afirmamos que Hl é corroborada.

Em relação a $\mathrm{H2}, \mathrm{H} 3$ e $\mathrm{H} 4$, os resultados não confirmam as hipóteses. Indivíduos que tiveram contato com atos corruptos no México e Peru, na Costa Rica e Nicarágua e no Chile e Uruguai não apresentam, sucessivamente, magni- 
tude decrescente de razão de chance de engajamento em atividades participativas. Tal cenário se aplica a toda série histórica e também às quatro modalidades de participação. Para melhor ilustrar essa constatação, sintetizamos, na Tabela 6, a sequência de magnitude de valores de associação entre experiência com corrupção e engajamento participativo, por rodada, grupo de países e modalidade de participação. Os dados dessa tabela advêm dos testes de regressão expostos nas Tabelas 2 a 5.

A partir desses resultados, constatamos que a magnitude do efeito da corrupção na participação política independe do grau de corrupção do país. Ou seja, a intensidade de socialização com atos corruptos não importa para entender a força da relação estudada.

\section{VII.2. A tolerância à corrupção entre diferentes perfis sociais}

${ }^{8}$ Para maiores esclarecimentos sobre a leitura dos resultados, indicamos também a consulta a tabelas presentes no Apêndice: aquelas relativas aos valores preditos para as demais rodadas e as pertinentes à síntese de resultados sobre maior e menor permissividade à corrupção. A leitura dos resultados se dá em termos de probabilidade.
Feito o diagnóstico do tipo de relação entre corrupção e participação política, focamos agora as consequências comportamentais da conjunção desses dois elementos. Especificamente, analisamos se o indivíduo que alia experiência com corrupção e ativismo político mostra-se mais tolerante ou menos tolerante a uma prática usual de corrupção, o pagamento de propina. Dessa forma, passamos do estágio de diagnóstico, de verificação sobre a associação entre experiência com corrupção e engajamento político, para o das consequências dessa relação: seria o indivíduo ao mesmo tempo exposto a práticas de corrupção e engajado politicamente oposto a uma prática usual de corrupção ou teria ele um comportamento mais resignado a respeito?

Cabe relembrar os quatro perfis sociais criados para essa investigação: (1) Experiente com corrupção + ativista político; (2) experiente com corrupção + não ativista político; (3) inexperiente com corrupção + ativista político; (4) inexperiente com corrupção + não ativista político.

Para fazermos a comparação da permissividade à corrupção entre esses quatro perfis sociais, aplicamos o teste de valores preditos (Gráficos 1, 2 e 3) , $^{8}$ que informa a probabilidade de ser tolerante ao pagamento de propina para cada um dos perfis. O principal resultado é a verificação de que os perfis que apresentam maior permissividade ao pagamento de propina sempre contêm a experiência com corrupção como um de seus componentes. Contudo, a observação do conjunto de resultados não nos permite apontar um perfil social específico como o mais permissivo ao pagamento de propina, já que não há uma tendência comum entre anos, modalidades de participação e grupos de países. O único achado que se pode extrair dos resultados é que possuir experiência com corrupção aumenta a probabilidade de tolerância ao pagamento de propina (Tabela 7). Com base nesses dados, os resultados não corroboram as H5 e H6.

Tabela 6 - Sequência decrescente de magnitude de associação entre experiência com corrupção e engajamento nas modalidades de participação

\begin{tabular}{lccc}
\hline & \multicolumn{1}{c}{2006} & $\mathbf{2 0 0 8}$ & $\mathbf{2 0 1 0}$ \\
\hline $\begin{array}{l}\text { Contato com atores políticos e } \\
\text { governamentais }\end{array}$ & MxPr $>$ ChUru $>$ CRNic & CRNic $>$ MxPr $>$ ChUru & ChUru $>$ MxPr $>$ CRNic \\
Ativismo comunitário & ChUru $>$ CRNic $>$ MxPr & ChUru $>$ CRNic $>$ MxPr & ChUru $>$ CRNic $>$ MxPr \\
Ativismo partidário e eleitoral & ChUru $>$ CRNic $>$ MxPr & ChUru $>$ MxPr $>$ CRNic & CRNic $>$ ChUru $>$ MxPr \\
Ativismo de protesto & MxPr $>$ CRNic $>$ ChUru & - & CRNic $>$ ChUru $>$ MxPr \\
\hline
\end{tabular}

Fonte: Os autores, a partir de Latin American Public Opinion Project (2010).

Nota: $\mathrm{ChUru}=$ Chile e Uruguai, $\mathrm{CRNic}=$ Costa Rica e Nicarágua e MxPr = México e Peru. 
Gráfico 1 - Predição de tolerância à propina por perfis sociais, Chile e Uruguai (2010)
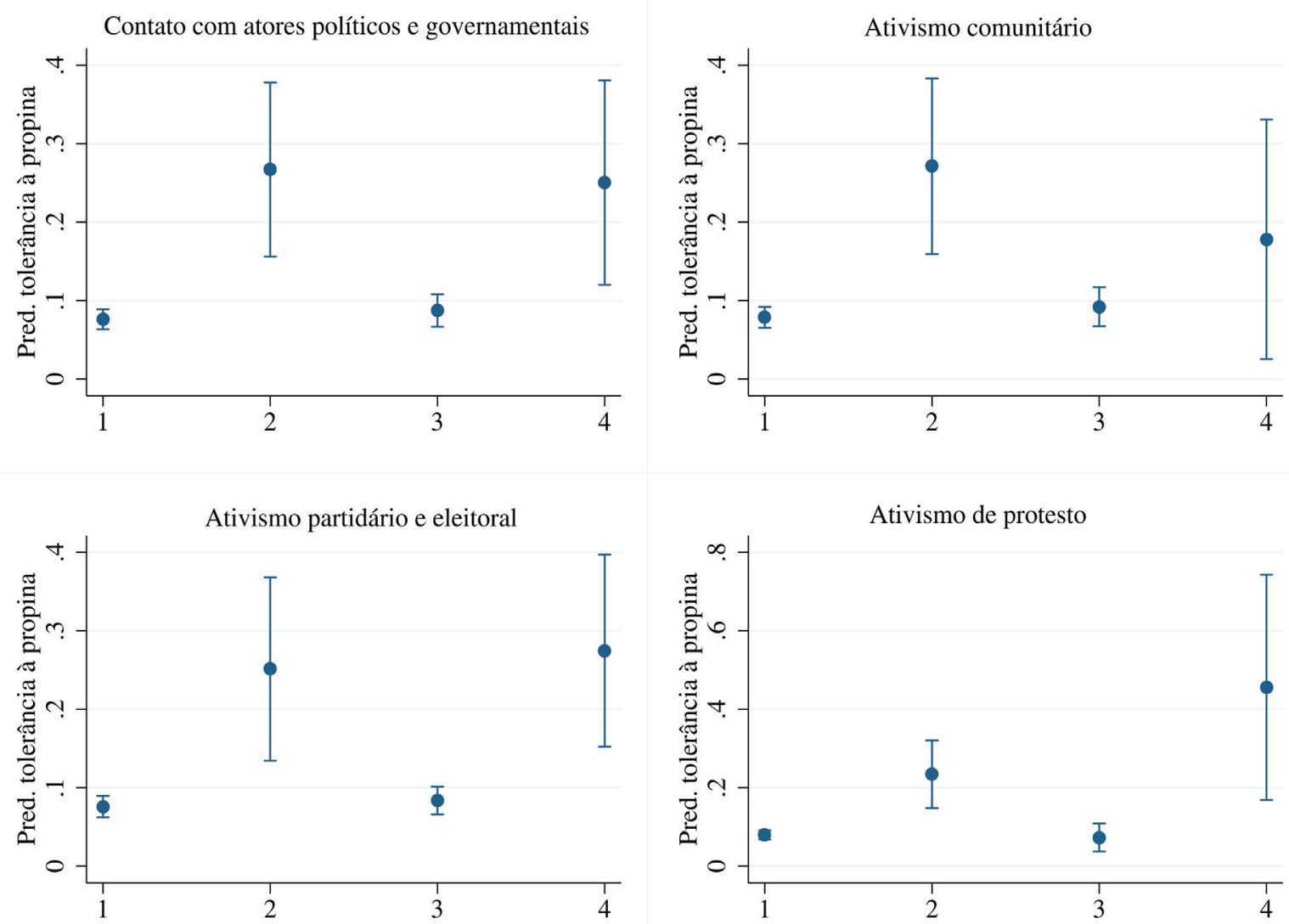

Fonte: Os autores, a partir de Latin American Public Opinion Project (2010).

Nota: 1 = não experiência e não participação; 2 = experiência e não participação; 3 = não experiência e participação; $4=$ experiência e participação.

Por outro lado, na situação extrema de não permissividade, essa característica - experiência com corrupção - jamais mostra-se presente. Independentemente se acompanhada ou não de participação, o perfil que contém como um dos componentes a não experiência com corrupção é sempre o menos permissivo ao pagamento de propina. Porém, identificamos o perfil que combina inexperiência com corrupção e não ativismo político é o predominante. Ou seja, esse perfil é o menos permissivo ao pagamento de propina na maior parte dos casos, considerando o período temporal, as modalidades de participação e os grupos de países (Tabela 8).

Ressaltamos um exemplo, no Quadro 2, que ilustra bem as duas tendências apontadas acima. Em ativismo partidário e eleitoral, a probabilidade de que indivíduos da Costa Rica e da Nicarágua que possuem experiência com corrupção e são ativistas políticos sejam tolerantes com o pagamento de propina é de $31 \%$, ao passo que a probabilidade de indivíduos conterrâneos que não possuem experiência com corrupção e que não são ativistas políticos de terem o mesmo posicionamento é de apenas 9\%. Esse caso e vários outros retratados nos gráficos e tabelas abaixo indicam a existência de uma relevante distância da permissividade à corrupção entre os perfis que envolvem o contato ou não com atos corruptos.

Cabe observar que, quase na totalidade dos casos, os intervalos de confiança dos perfis criados passam pelos mesmos valores ${ }^{9}$. Embora isso impeça uma 
Gráfico 2 - Predição de tolerância à propina por perfis sociais, Costa Rica e Nicarágua (2010)
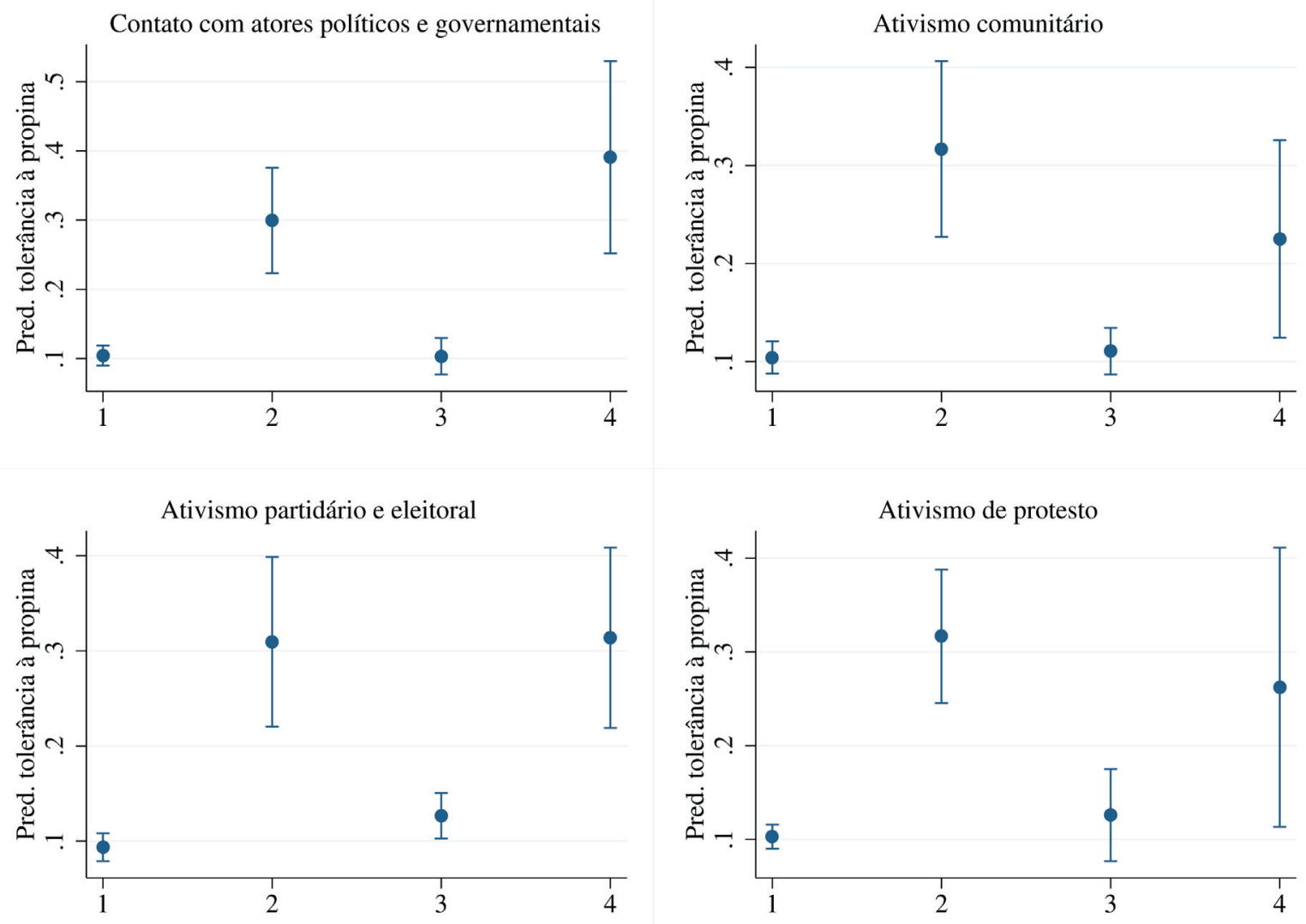

Fonte: Os autores, a partir de Latin American Public Opinion Project (2010).

Nota: 1 = não experiência e não participação; 2 = experiência e não participação; 3 = não experiência e participação; 4 = experiência e participação.

\section{Conclusões}

\footnotetext{
${ }^{9}$ Essa constatação só pode ser aferida via criação de gráficos de valores preditos para todas as rodadas de dados. Não expomos esses resultados por economia de espaço, mas eles podem ser obtidos via aplicação dos comandos dos testes estatísticos - presentes nas sintaxes - nos bancos de dados utilizados pelos autores. Para conseguir ambos, basta entrar em contato com os autores.
}

conclusão mais categórica a respeito dos resultados encontrados, ressaltamos que a presença de padrões consistentes ao longo dos anos embasa as nossas considerações.
Nesse artigo, investigamos um problema de pesquisa pouco explorado e acreditamos que os resultados alcançados contribuem para os estudos sobre a relação entre corrupção e comportamento político.

Primeiro, o estudo confirma a natureza multidimensional da participação política. As modalidades de participação política sugeridas neste estudo guardam estreita relação com as indicadas por Booth e Seligson (2009) e por Bonifácio e Paulino (2015). Ademais, resultados similares presentes em Verba, Nie e Kim (1987), Norris (2002) e Teorell, Torcal e Montero (2007), que se baseiam em dezenas de países de variados continentes e que utilizam distintos bancos de dados, favorecem a interpretação de que a multidimensionalidade da participação política tem abrangência global. Além disso, pode-se afirmar que os caminhos da manifestação desse fenômeno passam, necessariamente, pelo contato direto do cidadão com atores políticos, pelas arenas local e eleitoral de demandas política e por expressões políticas contestatórias. 
Gráfico 3 - Predição de tolerância à propina por perfis sociais, México e Peru (2010)
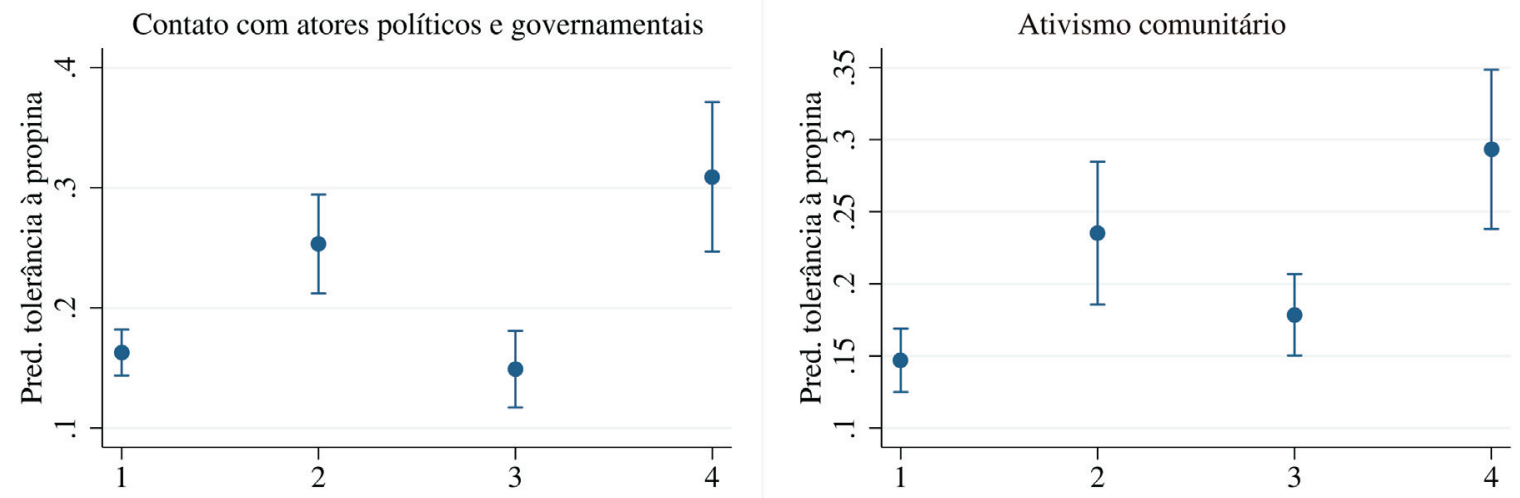

Ativismo partidário e eleitoral
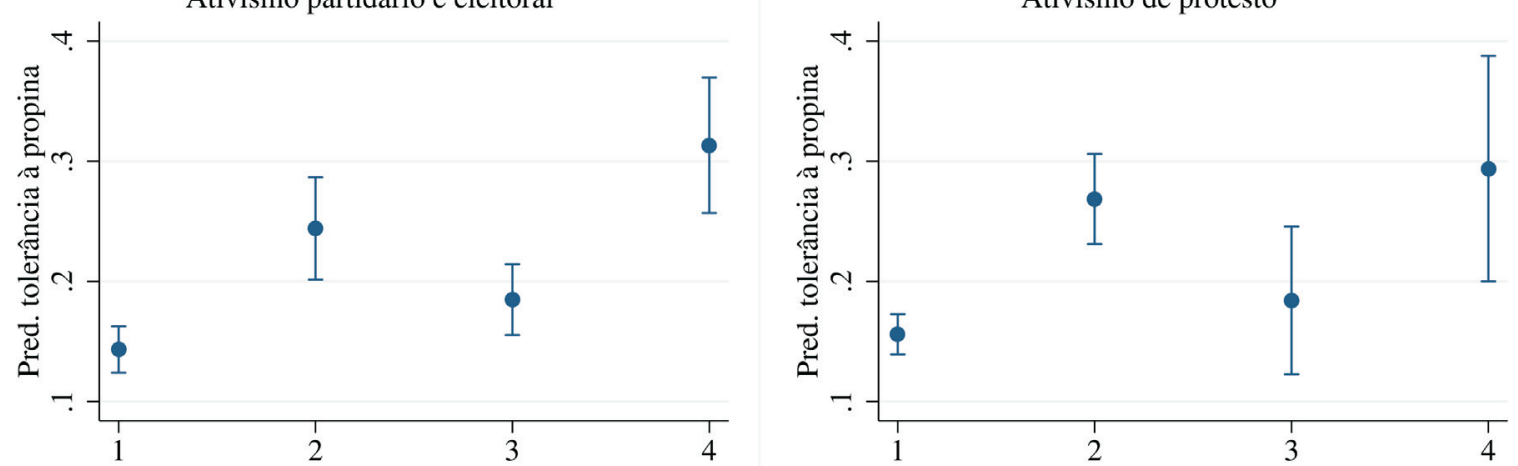

Fonte: Os autores, a partir de Latin American Public Opinion Project (2010).

Nota: 1 = não experiência e não participação; 2 = experiência e não participação; 3 = não experiência e participação; 4 = experiência e participação.

Tabela 7 - Síntese dos resultados de maiores permissividades à corrupção (tolerância ao pagamento de propina)

\begin{tabular}{|c|c|c|c|c|c|c|c|c|c|}
\hline & \multicolumn{3}{|c|}{ Chile e Uruguai } & \multicolumn{3}{|c|}{ Costa Rica e Nicarágua } & \multicolumn{3}{|c|}{ México e Peru } \\
\hline & 2006 & 2008 & 2010 & 2006 & 2008 & 2010 & 2006 & 2008 & 2010 \\
\hline CAPG & Situação 1 & Situação 2 & Situação 1 & Situação 2 & Situação 1 & Situação 2 & Situação 2 & Situação 1 & Situação 2 \\
\hline $\mathrm{AC}$ & Situação 1 & Situação 2 & Situação 1 & Situação 1 & Situação 1 & Situação 1 & Situação 1 & Situação 2 & Situação 2 \\
\hline APE & Situação 1 & Situação 1 & Situação 2 & Situação 2 & Situação 2 & Situação 2 & Situação 1 & Situação 1 & Situação 2 \\
\hline $\mathrm{AP}$ & Situação 2 & - & Situação 2 & Situação 1 & - & Situação 1 & Situação 1 & - & Situação 2 \\
\hline
\end{tabular}

Fonte: Os autores, a partir de Latin American Public Opinion Project (2010).

Nota: Situação 1 = experiência com corrupção e não participação política; Situação 2 = experiência com corrupção e participação política. $\mathrm{CAPG}=$ contato com atores políticos e governamentais. $\mathrm{AC}=$ ativismo comunitário. $\mathrm{APE}=$ ativismo partidário e eleitoral. $\mathrm{AP}=$ ativismo de protesto.

Sobre a relação entre corrupção e participação política, identificamos um padrão robusto de associação positiva entre os dois fenômenos. Em todas as modalidades de participação, durante todo o período temporal analisado e mesmo com a inclusão de variáveis explicativas concorrentes, a interpretação dos dados confirma que os indivíduos que passaram por situações de pedido de propina por funcionário público e policial são mais propensos a se engajar em atividades participativas. 
Tabela 8 - Síntese dos resultados de menores permissividades à corrupção (tolerância ao pagamento de propina)

\begin{tabular}{|c|c|c|c|c|c|c|c|c|c|}
\hline & \multicolumn{3}{|c|}{ Chile e Uruguai } & \multicolumn{3}{|c|}{ Costa Rica e Nicarágua } & \multicolumn{3}{|c|}{ México e Peru } \\
\hline & 2006 & 2008 & 2010 & 2006 & 2008 & 2010 & 2006 & 2008 & 2010 \\
\hline CAPG & Situação 3 & Situação 3 & Situação 3 & Situação 3 & Situação 4 & Situação 3 & Situação 3 & Situação 3 & Situação 4 \\
\hline $\mathrm{AC}$ & Situação 3 & Situação 3 & Situação 3 & Situação 3 & Situação 4 & Situação 3 & Situação 3 & Situação 3 & Situação 3 \\
\hline APE & Situação 3 & Situação 4 & Situação 3 & Situação 3 & Situação 3 & Situação 3 & Situação 3 & Situação 3 & Situação 3 \\
\hline AP & Situação 4 & - & Situação 4 & Situação 3 & - & Situação 3 & Situação 3 & - & Situação 3 \\
\hline
\end{tabular}

Fonte: Os autores, a partir de Latin American Public Opinion Project (2010).

Nota: Situação 3 = não experiência com corrupção e não participação política. Situação 4 = não experiência com corrupção e participação política. $\mathrm{CAPG}=$ contato com atores políticos e governamentais. $\mathrm{AC}=$ ativismo comunitário. $\mathrm{APE}=$ ativismo partidário e eleitoral. $\mathrm{AP}=$ ativismo de protesto.

Pareceu-nos também importante qualificar essa relação. Observamos que a convivência com a corrupção está ligada à maior tolerância com uma das formas de manifestação do fenômeno. O indivíduo tocado pela corrupção tende a conformar-se com a sua presença na sociedade, em vez de mostrar-se indignado com tal situação. Por outro lado, no que se refere ao posicionamento de repulsa à hipotética situação de pagamento de propina, o perfil que combina ausência de experiência com corrupção e não ativismo político mostra-se o mais propenso a exercê-lo.

A vantagem da aplicação do desenho de pesquisa comparada para a análise dos dois conjuntos de questões acima é a verificação de que as tendências relacionadas são uniformes, pois não variam de acordo com um contexto de maior ou menor corrupção. Ou seja, os efeitos nocivos da corrupção para a democracia são parecidos em sociedades com diferentes níveis de manifestação do fenômeno. Isso significa que a corrupção é nociva a quem por ela é tocado, independente do contexto. O que varia é o contingente de indivíduos por ela afetada.

Quais são as consequências da corrupção para a democracia, considerando esse conjunto de resultados? Primeiramente, é preciso revisitar criticamente a tese de Hirschman (1987): ser tocado pela corrupção não leva o indivíduo a abandonar o perfil cívico, nesse caso, não leva ao abandono do ativismo político. Pelo contrário: há robusta associação entre experiência com corrupção e engajamento político. Por outro lado, ela tem o potencial de desencantamento. Nesse sentido, os resultados encontrados têm estreita relação com as teses de Warren (2012): ser tocado pela corrupção não apenas conduz à participação, mas traz também efeitos nocivos ao civismo. O que conseguimos identificar, especificamente, é que os indivíduos que vivenciaram situações de pedido de propina por parte de agentes públicos são os mais tolerantes ao pagamento de propina. E parece-nos razoável supor que que esse tipo de posicionamento se aplique a outras formas de manifestação da corrupção.

Esperávamos que a magnitude da associação entre experiência com corrupção e ativismo político fosse maior em contextos onde a corrupção é mais alastrada. Tal hipótese não foi verificada, uma vez que os resultados mostraram pouca variação nos efeitos da corrupção sobre o comportamento político. Isso, contudo, não leva à interpretação de que o alastramento de práticas corruptas numa sociedade não seja relevante. Pelo contrário, conforme comentado no início do artigo, a corrupção tem efeitos negativos sobre o comportamento político do cidadão comum, em especial sobre atitudes democráticas. E, quanto mais frequente são os atos corruptos, mais arenas serão afetadas pelos seus efeitos. 
A despeito da grande quantidade de trabalhos sobre a relação entre a corrupção e atitudes políticas, poucos estudos se preocuparam com a participação política. Este artigo buscou contribuir nesse sentido, especificamente em relação à experiência que envolve o contato do cidadão com práticas de corrupção. Com os dados disponíveis, a imagem que fica é ambivalente: de um lado, essa experiência estimula a participação política e, de outro, quando combinada com a participação política, ela gera maior tolerância à corrupção.

Robert Bonifácio (rbonisilva@gmail.com) é Doutor em Ciência Política pela Universidade Federal de Minas Gerais (UFMG) e Professor de Ciência Política na Universidade Federal de Goiás (UFG). Vínculo Institucional: Programas de Pós-Graduação em Ciência Política e em Direito e Políticas Públicas, UFG, Goiânia, GO, Brasil.

Mario Fuks (mariofuks@ gmail.com) é Doutor em Ciência Política pelo Instituto Universitário de Pesquisas do Rio de Janeiro (Iuperj) Professor de Ciência Política na Universidade Federal de Minas Gerais (UFMG). Vínculo Institucional: Departamento de Ciência Política, UFMG, Belo Horizonte, MG, Brasil.

\section{Referências}

Bohn, S., 2012. Corruption in Latin America: Understanding the Perception-Exposure Gap. Journal of Politics in Latin America, 4(3), pp.67-95.

Bonifácio, R. \& Paulino, R., 2015. Corruption and Participation in the Americas and the Caribbean. Brazilian Political Science Review, 9(2), pp.54-80. DOI: 10.1590/1981-38212014000200011

Booth, J. \& Seligson, M., 2009. The Legitimacy Puzzle in Latin America: Political Support and Democracy in Eight Nations. Cambridge, UK: Cambridge University Press.

Borba, J., 2012. Participação política: uma revisão dos modelos de classificação. Sociedade e Estado, 27(2), pp.263-288. DOI: 10.1590/s0102-69922012000200004

Brady, H., 1999. Political Participation. In J. Robinson, ed. Measures of Political Attitudes. San Diego: Academic Press.

Converse, P., 1972. Change in the American Electorate. In A. Campbell \& P. Converse, eds. The Human Meaning of Social Change. New York: Russel Sage Foundation.

Drasgow, F., 1998. Polychoric and Polyserial Correlations. In J. Johnson, ed. Encyclopedia of Statistical Sciences. V. 7. New York: Wiley.

Fialho, F. (2008). Participação e desigualdade política: um exercício em teoria e método. Dissertação de Mestrado. Belo Horizonte: Universidade Federal de Minas Gerais.

Gorsuch, R., 1983. Factor Analysis. Hillsdale: Erlbaum.

Hirschman, A., 1983. De consumidor a cidadão: atividades privadas e participação na vida pública. São Paulo: Brasiliense.

King, G.; Keohane, R. \& Verba, S., 1994. Designing Social Inquiry. Princeton: Princeton University Press.

Milbrath, L., 1965. Political Participation: How and Why Do People Get Involved in Politics? Chicago: Rand McNally and Company.

Neuman, R., 1986. The Paradox of Mass Politics: Knowledge and Opinion in the American Electorate. Cambridge, MA: Harvard University Press.

Norris, P., 2002. Democratic Phoenix: Reinventing Political Activism. Cambridge, UK: Cambridge University Press.

Olsson, S., 2014. Corruption and Political Participation: A Multilevel Analysis. QoG Working Papers Series, 12, pp.1-53.

Reis, F., 2000. Mercado e utopia: teoria política e sociedade brasileira. São Paulo: Edusp.

Salinas, E. \& Booth, J., 2011. Micro-Social and Contextual Sources of Democratic Attitudes in Latin America. Journal of Politics in Latin American, 3(1), pp. 29-64.

Seligson, M., 2001. Corruption and Democratization: What is to be Done? Public Integrity, 3(3), pp.221-241. DOI: $10.1080 / 15580989.2001 .11770873$ , 2002. The Impact of Corruption on Regime Legitimacy: A Comparative Study of four Latin American Countries. Journal of Politics, 64(2), pp.408-433. DOI: 10.1111/1468-2508.00132

Teorell, J.; Torcal, M. \& Montero, J., 2007. Political Participation: Mapping the Terrain. In J. Van Deth; J. Montero \& A. Westholm, eds. Citizenship and Involvement in European Democracies: A Comparative Analysis. New York: Routledge.

Verba, S.; Nie, N. \& Kim, J., 1987. Participation and Political Equality: A Seven-Nation Comparison. New York: University of Chicago Press.

Warren, M., 2012. The Meaning of Corruption in Democracies. In: P. Heywood, ed. The Routledge International Handbook on Political Corruption. Oxford: Routledge.

Zéphyr, D. (2008). Corruption and Its Impact on Latin American Democratic Stability. In M. Seligson, ed. Challenges to Democracies in Latin American and the Caribbean: Evidence from the Americas Barometer 2006-2007. Vanderbilt University/United States Agency for International Development.

\section{Outras fontes}

Latin American Public Opinion Project, 2010. Data Sets. Vanderbilt University. Disponível em: http://vanderbilt.edu/lapop/raw-data.php. Acesso em: 5 ago. 2017. 
Unraveling the Relationship Between Corruption and Political Participation in Latin America: Diagnosis and Impacts of Disclosure to Corrupt Acts on Political Participation

\section{Abstract}

We investigate the relationship between corruption and political participation in Latin America. We selected three blocks of countries that are situated in low, intermediary and high position in Experience of Corruption Ranking: Chile and Uruguay, Costa Rica and Nicaragua and Mexico and Peru, respectively. Our analysis occurs in individual level and we use as data source the Americas Barometer (2006) (2008) and 2010 rounds. We point as principal results: (1) the identification of four types of political participation; (2) a positive association between corruption and political participation, considering all rounds and all blocks of countries; and (3) the greater tolerance of corruption among individuals that have experienced corruption, regardless of this feature being followed by political activism.

KEYWORDS: Corruption; Political Participation; Corruption Permittivity; Latin America; Barometer of the Americas.

This is an Open Access article distributed under the terms of the Creative Commons Attribution Non-Commercial License which permits unrestricted non-commercial use, distribution, and reproduction in any medium provided the original work is properly cited. 


\section{Apêndices. Resultados de testes estatísticos realizados}

Destacamos que todos os resultados encontrados foram obtidos a partir de análise de dados do Barômetro das Américas, rodadas de 2006 (2008) e 2010.

Tabela 1A - Frequência e número de casos do indicador de experiência com corrupção, por rodada

\begin{tabular}{lccc}
\hline & $\mathbf{2 0 0 6}$ & $\mathbf{2 0 0 8}$ & $\mathbf{2 0 1 0}$ \\
\hline Chile e Uruguai & 3,5 & 3,7 & 4,2 \\
& $(105)$ & $(110)$ & $(125)$ \\
Costa Rica e Nicarágua & 10,2 & 10,8 & 8,0 \\
& $(305)$ & $(320)$ & $(239)$ \\
México e Peru & 24,5 & 22,0 & 24,9 \\
& $(733)$ & $(588)$ & $(742)$ \\
\hline
\end{tabular}

Fonte: Os autores, a partir de Latin American Public Opinion Project (2010).

Nota: Os valores em cada célula estão em percentuais válidos, que excluem os casos ausentes (missing values). Em parêntesis, a quantidade de casos.

Tabela 2A - Frequência e ranking de experiência com corrupção na América Latina, pois país e rodada

\begin{tabular}{|c|c|c|c|c|c|c|c|c|}
\hline \multicolumn{3}{|c|}{2006} & \multicolumn{3}{|c|}{2008} & \multicolumn{3}{|c|}{2010} \\
\hline Posição & País & Percentual & Posição & País & Percentual & Posição & País & Percentual \\
\hline $\mathbf{1}^{\mathrm{o}}$ & México & 26,1 & $1^{\circ}$ & Bolívia & 23,7 & $1^{o}$ & México & 27,6 \\
\hline $2^{\circ}$ & Bolívia & 24,2 & $2^{\circ}$ & México & 20,8 & $2^{\circ}$ & Bolívia & 22,5 \\
\hline $3^{\circ}$ & Peru & 22,9 & $3^{\circ}$ & Peru & 20,5 & $3^{\circ}$ & Peru & 22,2 \\
\hline $4^{\circ}$ & Equador & 21,6 & $3^{\circ}$ & Guiana & 19,5 & $4^{\circ}$ & Paraguai & 17,1 \\
\hline $5^{\circ}$ & Paraguai & 18,1 & $4^{\circ}$ & Argentina & 18,8 & $5^{\circ}$ & Haiti & 16,5 \\
\hline $6^{\circ}$ & Venezuela & 16,5 & $5^{\circ}$ & Equador & 16,0 & $6^{\circ}$ & Guatemala & 16,0 \\
\hline $7^{\circ}$ & Haiti & 14,9 & $6^{\circ}$ & Paraguai & 14,7 & $7^{\circ}$ & Argentina & 14,9 \\
\hline $8^{\circ}$ & Guiana & 13,3 & $7^{\circ}$ & Belize & 14,5 & $8^{\circ}$ & Guiana & 14,1 \\
\hline $9^{\circ}$ & $\begin{array}{c}\text { República } \\
\text { Dominicana }\end{array}$ & 12,9 & $8^{\circ}$ & Haiti & 13,9 & $9^{\circ}$ & Equador & 13,4 \\
\hline $10^{\circ}$ & Honduras & 12,8 & $9^{\circ}$ & Guatemala & 12,5 & $10^{\circ}$ & $\begin{array}{l}\text { República } \\
\text { Dominicana }\end{array}$ & 12,7 \\
\hline $11^{\circ}$ & Guatemala & 12,2 & $10^{\circ}$ & Nicarágua & 11,3 & $11^{\circ}$ & Belize & 12,3 \\
\hline $12^{\circ}$ & Costa Rica & 11,2 & $11^{\circ}$ & $\begin{array}{c}\text { República } \\
\text { Dominicana }\end{array}$ & 11,2 & $12^{\circ}$ & Venezuela & 11,9 \\
\hline $13^{\circ}$ & Nicarágua & 9,1 & $12^{\circ}$ & Costa Rica & 10,5 & $12^{\circ}$ & Honduras & 11,1 \\
\hline $14^{\circ}$ & Panamá & 8,0 & $13^{\circ}$ & Honduras & 9,5 & $13^{\circ}$ & Nicarágua & 8,8 \\
\hline $15^{\circ}$ & El Salvador & 7,8 & $14^{\circ}$ & El Salvador & 8,5 & $14^{\circ}$ & Colômbia & 7,9 \\
\hline $16^{\circ}$ & Jamaica & 7,7 & $15^{\circ}$ & Jamaica & 6,8 & $14^{\circ}$ & Suriname & 7,9 \\
\hline $17^{\circ}$ & Colômbia & 5,9 & $16^{\circ}$ & Colômbia & 6,5 & $15^{\circ}$ & El Salvador & 7,7 \\
\hline $18^{\circ}$ & Brasil & 5,7 & $17^{\circ}$ & Venezuela & 6,4 & $16^{\circ}$ & Costa Rica & 7,3 \\
\hline $19^{\circ}$ & Uruguai & 3,9 & $18^{\circ}$ & Panamá & 4,9 & $17^{\circ}$ & Brasil & 6,7 \\
\hline \multirow[t]{6}{*}{$20^{\circ}$} & Chile & 3,1 & $18^{\circ}$ & Uruguai & 4,9 & $17^{\circ}$ & $\begin{array}{l}\text { Trinidade e } \\
\text { Tobago }\end{array}$ & 6,7 \\
\hline & & & $19^{\circ}$ & Brasil & 3,9 & $18^{\circ}$ & Jamaica & 5,9 \\
\hline & & & $20^{\circ}$ & Chile & 2,4 & $19^{\circ}$ & Uruguai & 5,5 \\
\hline & & & & & & $20^{\circ}$ & Panamá & 5,3 \\
\hline & & & & & & $21^{\circ}$ & Chile & 2,9 \\
\hline & Média & $\begin{array}{c}11,8 \\
(3384) \\
\end{array}$ & & Média & $\begin{array}{c}11,1 \\
(4012) \\
\end{array}$ & & Média & $\begin{array}{c}11,2 \\
(4351) \\
\end{array}$ \\
\hline
\end{tabular}

Fonte: Os autores, a partir de Latin American Public Opinion Project (2010).

Nota: Os valores em cada célula estão em percentuais válidos, que excluem os casos ausentes (missing values). Para a média, os valores em parêntesis representam a quantidade de casos. 
Tabela 3A - Frequência e número de casos dos indicadores de participação política dos blocos de países, por modalidade e rodada

\begin{tabular}{|c|c|c|c|c|c|c|c|c|c|}
\hline & \multicolumn{3}{|c|}{ Chile e Uruguai } & \multicolumn{3}{|c|}{ Costa Rica e Nicarágua } & \multicolumn{3}{|c|}{ México e Peru } \\
\hline & 2006 & 2008 & 2010 & 2006 & 2008 & 2010 & 2006 & 2008 & 2010 \\
\hline CAPG & $\begin{array}{c}33,2 \\
(979)\end{array}$ & $\begin{array}{c}30,6 \\
(908)\end{array}$ & $\begin{array}{c}27,0 \\
(808)\end{array}$ & $\begin{array}{c}29,3 \\
(857)\end{array}$ & $\begin{array}{c}18,9 \\
(562)\end{array}$ & $\begin{array}{c}22,0 \\
(646)\end{array}$ & $\begin{array}{c}31,4 \\
(914)\end{array}$ & $\begin{array}{c}24,9 \\
(743)\end{array}$ & $\begin{array}{c}26,5 \\
(787)\end{array}$ \\
\hline $\mathrm{AC}$ & $\begin{array}{c}40,0 \\
(1193)\end{array}$ & $\begin{array}{c}24,4 \\
(628)\end{array}$ & $\begin{array}{c}23,1 \\
(595)\end{array}$ & $\begin{array}{c}37,5 \\
(1118)\end{array}$ & $\begin{array}{c}27,8 \\
(681)\end{array}$ & $\begin{array}{c}31,5 \\
(813)\end{array}$ & $\begin{array}{c}49,2 \\
(1453)\end{array}$ & $\begin{array}{c}40,0 \\
(1065)\end{array}$ & $\begin{array}{c}43,1 \\
(1118)\end{array}$ \\
\hline APE & $\begin{array}{c}38,6 \\
(1140)\end{array}$ & $\begin{array}{c}30,8 \\
(899)\end{array}$ & $\begin{array}{c}34,9 \\
(1035)\end{array}$ & $\begin{array}{c}40,1 \\
(1174)\end{array}$ & $\begin{array}{c}48,5 \\
(1394)\end{array}$ & $\begin{array}{c}33,5 \\
(984)\end{array}$ & $\begin{array}{c}43,1 \\
(1251)\end{array}$ & $\begin{array}{c}39,9 \\
(1168)\end{array}$ & $\begin{array}{c}36,4 \\
(1078)\end{array}$ \\
\hline AP & $\begin{array}{c}23,5 \\
(703)\end{array}$ & - & $\begin{array}{c}8,0 \\
(241)\end{array}$ & $\begin{array}{c}13,1 \\
(393)\end{array}$ & - & $\begin{array}{c}7,6 \\
(228)\end{array}$ & $\begin{array}{c}21,8 \\
(636)\end{array}$ & - & $\begin{array}{c}9,3 \\
(277)\end{array}$ \\
\hline
\end{tabular}

Fonte: Os autores, a partir de Latin American Public Opinion Project (2010).

Nota: $\mathrm{CAPG}=$ contato com atores políticos e governamentais; $\mathrm{AC}=$ ativismo comunitário; $\mathrm{APE}=$ ativismo partidário e eleitoral; $\mathrm{AP}$ = ativismo de protesto. Os valores em cada célula estão em percentuais válidos, que excluem os casos ausentes (missing values). Em parêntesis, a quantidade de casos.

Tabela 4A - Análise fatorial exploratória com os indicadores de participação política (2006)

\begin{tabular}{|c|c|c|c|c|c|c|c|c|c|}
\hline & \multicolumn{3}{|c|}{ Chile e Uruguai } & \multicolumn{3}{|c|}{$\begin{array}{c}\text { Costa Rica e } \\
\text { Nicarágua }\end{array}$} & \multicolumn{3}{|c|}{ México e Peru } \\
\hline & 1 & 2 & 3 & 1 & 2 & 3 & 1 & 2 & 3 \\
\hline Contato: Deputado estadual e federal & 0,715 & & & 0,751 & & & 0,770 & & \\
\hline Contato: Atores políticos governamentais & 0,631 & & & 0,683 & & & 0,764 & & \\
\hline Contato: Atores políticos locais & 0,847 & & & 0,726 & & & 0,811 & & \\
\hline Contato: Vereador & 0,641 & & & 0,555 & & & 0,572 & & \\
\hline Ação em prol da comunidade & & & 0,594 & & & 0,581 & & & 0.587 \\
\hline Assistir reunião de associação de bairro & & & 0,602 & & & 0,617 & & & 0.606 \\
\hline Assistir reunião de partido político & & 0,780 & & & 0,686 & & & 0,643 & \\
\hline Trabalho em campanha eleitoral & & 0,823 & & & 0,646 & & & 0,694 & \\
\hline Convencimento sobre escolha de voto & & 0,609 & & & 0,462 & & & 0,558 & \\
\hline Participar de protestos & & 0,548 & & & 0,317 & & & 0,378 & \\
\hline Alpha de Cronbach & & 0,574 & & & 0,573 & & 0,609 & & \\
\hline$K M O$ & & 0,736 & & & 0,776 & & 0,801 & & \\
\hline
\end{tabular}

Fonte: Os autores, a partir de Latin American Public Opinion Project (2010). 
Tabela 5A - Análise fatorial exploratória com os indicadores de participação política (2008)

\begin{tabular}{|c|c|c|c|c|c|c|c|c|c|}
\hline & \multicolumn{3}{|c|}{ Chile e Uruguai } & \multicolumn{3}{|c|}{$\begin{array}{l}\text { Costa Rica e } \\
\text { Nicarágua }\end{array}$} & \multicolumn{3}{|c|}{ México e Peru } \\
\hline & 1 & 2 & 3 & 1 & 2 & 3 & 1 & 2 & 3 \\
\hline Contato: Deputado estadual e federal & 0,663 & & & 0,731 & & & 0,766 & & \\
\hline Contato: Atores políticos governamentais & 0,650 & & & 0,767 & & & 0,788 & & \\
\hline Contato: Atores políticos locais & 0,825 & & & 0,899 & & & 0,864 & & \\
\hline Contato: Vereador & 0,675 & & & 0,814 & & & 0,704 & & \\
\hline Ação em prol da comunidade & & & 0,492 & & 0,594 & & & & 0.571 \\
\hline Assistir reunião de associação de bairro & & & 0,556 & & 0,622 & & & & 0.583 \\
\hline Assistir reunião de partido político & & 0,816 & & & & 0,534 & & 0,565 & \\
\hline Trabalho em campanha eleitoral & & 0,797 & & & & 0,597 & & 0,675 & \\
\hline Convencimento sobre escolha de voto & & 0,653 & & & & 0,394 & & 0,500 & \\
\hline Alpha de Cronbach & & 0,583 & & 0,579 & & 0,603 & & 0,583 & \\
\hline$K M O$ & & 0,739 & & 0,805 & & 0,797 & & 0,739 & \\
\hline
\end{tabular}

Fonte: Os autores, a partir de Latin American Public Opinion Project (2010).

Tabela 6A - Preditores de contato com atores políticos e governamentais (2006)

\begin{tabular}{|c|c|c|c|c|c|c|}
\hline & \multicolumn{2}{|c|}{ Chile e Uruguai } & \multicolumn{2}{|c|}{ Costa Rica e Nicarágua } & \multicolumn{2}{|c|}{ México e Peru } \\
\hline & 1 & 2 & 1 & 2 & 1 & 2 \\
\hline Experiência com corrupção & 39,3 & $44,5^{*}$ & 17,0 & 14,5 & $73,2 * * *$ & $72,1 * * *$ \\
\hline Interesse por política & & $39,8 * * *$ & & $45,7 * * *$ & & $55,0 * * *$ \\
\hline Escolaridade-Superior & & 6,9 & & $31,1 * *$ & & $71,1 * * *$ \\
\hline Sexo masculino & & $-23,0 * * *$ & & $-3,2$ & & 2,4 \\
\hline Idade & & 0,3 & & $1,1 * * *$ & & $1,4 * * *$ \\
\hline Renda familiar & & $-7,7 * * *$ & & 0,8 & & $-6,0 * * *$ \\
\hline Constante & $-50,7 * * *$ & $-42,3 * * *$ & $-60,0 * * *$ & $-80,0 * * *$ & $-60,0 * * *$ & $-80,4 * * *$ \\
\hline Qui quadrado & 2,5 & $49,2 * * *$ & 1,4 & $43,5^{* * *}$ & $36,8 * * *$ & $93,1 * * *$ \\
\hline R2 Nagelkerke & 0,001 & 0,024 & 0,001 & 0,023 & 0,018 & 0,050 \\
\hline$\%$ de acerto & 66,7 & 66,1 & 70,7 & 70,2 & 68,6 & 68,2 \\
\hline Log da pseudo-verossimilhança & 3736,2 & 3530,1 & 3527,2 & 3208,0 & 3578,2 & 3140,1 \\
\hline
\end{tabular}

Fonte: Os autores, a partir de Latin American Public Opinion Project (2010).

$*=\mathrm{p}$ valor menor/igual a 0,$10 ; * *=\mathrm{p}$ valor menor ou igual a 0,$05 ; * * *=\mathrm{p}$ valor menor ou igual a 0,01 . 
Tabela 7A - Preditores de ativismo comunitário (2006)

\begin{tabular}{|c|c|c|c|c|c|c|}
\hline & \multicolumn{2}{|c|}{ Chile e Uruguai } & \multicolumn{2}{|c|}{ Costa Rica e Nicarágua } & \multicolumn{2}{|c|}{ México e Peru } \\
\hline & 1 & 2 & 1 & 2 & 1 & 2 \\
\hline Experiência com corrupção & $83,4 * * *$ & $97,8 * * *$ & $69,0 * * *$ & $56,2 * * *$ & $28,9 * * *$ & $32,5 * * *$ \\
\hline Interesse por política & & $30,6^{* * *}$ & & $44,8 * * *$ & & $51,9 * * *$ \\
\hline Escolaridade- Superior & & $26,3 * *$ & & $48,7 * * *$ & & $49,5 * * *$ \\
\hline Sexo masculino & & $-3,6$ & & $33,0 * * *$ & & 8,5 \\
\hline Idade & & $1,7 * * *$ & & $1,2 * * *$ & & $2,1 * * *$ \\
\hline Renda familiar & & 0,9 & & 0,6 & & $-5,0 * * *$ \\
\hline Constante & $-35,0 * * *$ & $-75,0 * * *$ & $-43,2 * * *$ & $-77,0 * * *$ & $-8,8 * *$ & $-65,7$ \\
\hline Qui quadrado & $8,9 * * *$ & $78,0 * * *$ & $18,4 * * *$ & $90,7 * * *$ & $8,8 * * *$ & $93,7 * * *$ \\
\hline R2 Nagelkerke & 0,004 & 0,037 & 0,008 & 0,045 & 0,004 & 0,047 \\
\hline$\%$ de acerto & 60,3 & 59,7 & 62,5 & 62,3 & 52,7 & 57,4 \\
\hline Log da pseudo-verossimilhança & 3994,0 & 3729,0 & 3915,7 & 3518,4 & 4072,4 & 3516,0 \\
\hline
\end{tabular}

Fonte: Os autores, a partir de Latin American Public Opinion Project (2010).

$*$ = p valor menor/igual a 0,$10 ; * *=$ p valor menor ou igual a 0,$05 ; * * *=$ p valor menor ou igual a 0,01 .

Tabela 8A - Preditores de ativismo partidário e eleitoral (2006)

\begin{tabular}{|c|c|c|c|c|c|c|}
\hline & \multicolumn{2}{|c|}{ Chile e Uruguai } & \multicolumn{2}{|c|}{ Costa Rica e Nicarágua } & \multicolumn{2}{|c|}{ México e Peru } \\
\hline & 1 & 2 & 1 & 2 & 1 & 2 \\
\hline Experiência com corrupção & 84,4 & $76,4 * * *$ & $70,9 * * *$ & $47,2 * * *$ & $23,5^{* *}$ & 13,2 \\
\hline Interesse por política & & $131,6 * * *$ & & $153,1 * * *$ & & $100,6^{* * *}$ \\
\hline Escolaridade- Superior & & $29,8 * *$ & & $34,2 * *$ & & $42,5 * * *$ \\
\hline Sexo masculino & & $52,1 * * *$ & & $44,8 * * *$ & & $35,4 * * *$ \\
\hline Idade & & 0,2 & & 0,1 & & 0,3 \\
\hline Renda familiar & & $11,1 * * *$ & & $-0,7$ & & 0,8 \\
\hline Constante & $-38,7 * * *$ & $-84,5 * * *$ & $-36,7 * * *$ & $-71,0 * * *$ & $-28,0 * * *$ & $-70,0 * * *$ \\
\hline Qui quadrado & $9,3 * * *$ & $255,5 * * *$ & $19,2 * * *$ & $171,5 * * *$ & $5,9 * *$ & $100,8 * * *$ \\
\hline R2 Nagelkerke & 0,004 & 0,118 & 0,009 & 0,084 & 0,003 & 0,052 \\
\hline$\%$ de acerto & 61,7 & 65,2 & 60,3 & 61,7 & 56,9 & 58,6 \\
\hline Log da pseudo-verossimilhança & 3927,1 & 3480,9 & 3914,7 & 3446,4 & 3496,0 & 3414,8 \\
\hline
\end{tabular}

Fonte: Os autores, a partir de Latin American Public Opinion Project (2010).

$*=$ p valor menor/igual a 0,$10 ; * *=$ p valor menor ou igual a 0,$05 ; * * *=p$ valor menor ou igual a 0,01 . 
Tabela 9A - Preditores de ativismo de protesto (2006)

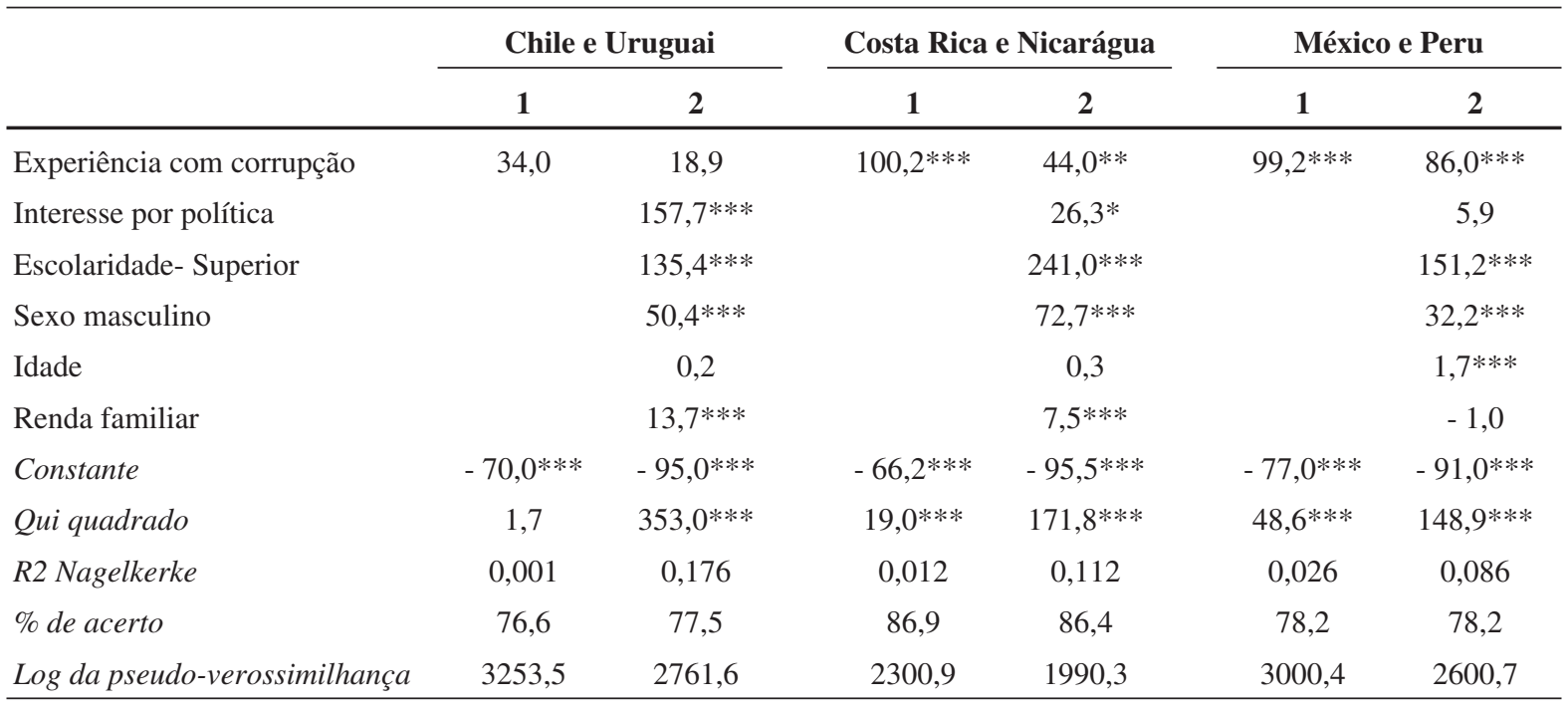

Fonte: Os autores, a partir de Latin American Public Opinion Project (2010).

$*$ = p valor menor/igual a 0,$10 ; * *=$ p valor menor ou igual a 0,$05 ; * * *=$ p valor menor ou igual a 0,01 .

==t1 Tabela $10 \mathrm{~A}-$ Preditores de contato com atores políticos e governamentais (2008)

\begin{tabular}{|c|c|c|c|c|c|c|}
\hline & \multicolumn{2}{|c|}{ Chile e Uruguai } & \multicolumn{2}{|c|}{ Costa Rica e Nicarágua } & \multicolumn{2}{|c|}{ México e Peru } \\
\hline & 1 & 2 & 1 & 2 & 1 & 2 \\
\hline Experiência com corrupção & 39,3 & $44,5^{*}$ & $50,6 * * *$ & $57,8 * * *$ & $44,1 * * *$ & $57,2 * * *$ \\
\hline Interesse por política & & $39,8 * * *$ & & $35,0 * * *$ & & $56,7 * * *$ \\
\hline Escolaridade- Superior & & 6,9 & & $34,2 * *$ & & $92,1 * * *$ \\
\hline Sexo masculino & & $-23,0 * * *$ & & 5,9 & & $-16,2^{*}$ \\
\hline Idade & & 0,3 & & $1,3 * * *$ & & $1,6 * * *$ \\
\hline Renda familiar & & $-7,7 * * *$ & & $-6,7 * * *$ & & $-12,4 * * *$ \\
\hline Constante & $-50,0 * * *$ & $-42,3 * * *$ & $-78,0 * * *$ & $-86,4 * * *$ & $-70,0 * * *$ & $-80,0 * * *$ \\
\hline Qui quadrado & 2,5 & $49,2 * * *$ & $8,1 * * *$ & $43,1 * * *$ & $12,1 * * *$ & $94,9 * * *$ \\
\hline R2 Nagelkerke & 0,001 & 0,024 & 0,004 & 0,026 & 0,007 & 0,058 \\
\hline$\%$ de acerto & 66,7 & 66,1 & 81,0 & 81,1 & 75,0 & 74,8 \\
\hline Log da pseudo-verossimilhança & 3736,2 & 3530,1 & 2865,9 & 2563,0 & 2984,8 & 2592,7 \\
\hline
\end{tabular}

Fonte: Os autores, a partir de Latin American Public Opinion Project (2010).

$*=$ p valor menor/igual a 0,$10 ; * *=$ p valor menor ou igual a 0,$05 ; * * *=p$ valor menor ou igual a 0,01 . 
Tabela 11A - Preditores de ativismo comunitário (2008)

\begin{tabular}{|c|c|c|c|c|c|c|}
\hline & \multicolumn{2}{|c|}{ Chile e Uruguai } & \multicolumn{2}{|c|}{ Costa Rica e Nicarágua } & \multicolumn{2}{|c|}{ México e Peru } \\
\hline & 1 & 2 & 1 & 2 & 1 & 2 \\
\hline Experiência com corrupção & $83,4 * * *$ & $97,8 * * *$ & $60,1 * * *$ & $63,9 * * *$ & $32,6 * * *$ & $41,9 * * *$ \\
\hline Interesse por política & & $30,6^{* * *}$ & & $73,2 * * *$ & & $59,9 * * *$ \\
\hline Escolaridade- Superior & & $26,3 * *$ & & $-4,4$ & & $43,9 * * *$ \\
\hline Sexo masculino & & $-3,6$ & & $22,3 * *$ & & 9,4 \\
\hline Idade & & $1,7 * * *$ & & $0,9 * * *$ & & $1,6 * * *$ \\
\hline Renda familiar & & 0,9 & & $-2,0$ & & $-10,9 * * *$ \\
\hline Constante & $-35,0 * * *$ & $-75,0 * * *$ & $-63,4 * * *$ & $-81,7 * * *$ & $-38,8 * * *$ & $-63,0 * * *$ \\
\hline Qui quadrado & $8,9 * * *$ & $78,0 * * *$ & $10,5^{* * *}$ & $61,2 * * *$ & $7,6 * * *$ & $86,8^{* * *}$ \\
\hline R2 Nagelkerke & 0,004 & 0,037 & 0,006 & 0,040 & 0,004 & 0,055 \\
\hline$\%$ de acerto & 60,3 & 59,7 & 72,2 & 72,5 & 60,6 & 60,8 \\
\hline Log da pseudo-verossimilhança & 3994,0 & 3729,0 & 2872,6 & 2554,5 & 3183,4 & 2754,7 \\
\hline
\end{tabular}

Fonte: Os autores, a partir de Latin American Public Opinion Project (2010).

$*$ = p valor menor/igual a 0,$10 ; * *=$ p valor menor ou igual a 0,$05 ; * * *=$ p valor menor ou igual a 0,01 .

Tabela 12A - Preditores de ativismo partidário e eleitoral (2008)

\begin{tabular}{|c|c|c|c|c|c|c|}
\hline & \multicolumn{2}{|c|}{ Chile e Uruguai } & \multicolumn{2}{|c|}{ Costa Rica e Nicarágua } & \multicolumn{2}{|c|}{ México e Peru } \\
\hline & 1 & 2 & 1 & 2 & 1 & 2 \\
\hline Experiência com corrupção & $84,4 * * *$ & $76,4 * * *$ & $47,1 * * *$ & $24,8^{*}$ & $47,8 * * *$ & $29,6 * *$ \\
\hline Interesse por política & & $131,6 * * *$ & & $154,8 * * *$ & & $143,4 * * *$ \\
\hline Escolaridade- Superior & & $29,8 * *$ & & 11,6 & & $35,9 * * *$ \\
\hline Sexo masculino & & $52,1 * * *$ & & $71,5^{* * *}$ & & 5,4 \\
\hline Idade & & 0,2 & & $-0,1$ & & $0,5^{*}$ \\
\hline Renda familiar & & $11,1 * * *$ & & 2,6 & & $-2,1$ \\
\hline Constante & $-38,7 * * *$ & $-84,5 * * *$ & $-10,4 * * *$ & $-60,0 * * *$ & $-40,0 * * *$ & $-63,0 * * *$ \\
\hline Qui quadrado & $9,3 * * *$ & $255,5 * * *$ & $10,2 * * *$ & $212,5 * * *$ & $16,6^{* * *}$ & $106,2 * * *$ \\
\hline R2 Nagelkerke & 0,004 & 0,118 & 0,005 & 0,104 & 0,009 & 0,060 \\
\hline$\%$ de acerto & 61,7 & 65,2 & 53,2 & 61,6 & 60,3 & 60,7 \\
\hline Log da pseudo-verossimilhança & 3927,1 & 3480,9 & 3953,4 & 3413,4 & 3495,6 & 3034,3 \\
\hline
\end{tabular}

Fonte: Os autores, a partir de Latin American Public Opinion Project (2010).

$*=$ p valor menor/igual a 0,$10 ; * *=$ p valor menor ou igual a 0,$05 ; * * *=p$ valor menor ou igual a 0,01 . 
Tabela 13A - Predição de tolerância ao pagamento de propina de acordo com os perfis sociais (em probabilidade) - Contato com atores políticos e governamentais

\begin{tabular}{|c|c|c|c|c|c|c|c|c|c|}
\hline & \multicolumn{3}{|c|}{ Chile e Uruguai } & \multicolumn{3}{|c|}{ Costa Rica e Nicarágua } & \multicolumn{3}{|c|}{ México e Peru } \\
\hline & 2006 & 2008 & 2010 & 2006 & 2008 & 2010 & 2006 & 2008 & 2010 \\
\hline Combinação 1 & $0.14 * * *$ & $0.13 * * *$ & $0,07 * * *$ & $0.19 * * *$ & $0.18 * * *$ & $0,10 * * *$ & $0.19 * * *$ & $0.18 * * *$ & $0,16 * * *$ \\
\hline Combinação 2 & $0.26 * * *$ & $0.24 * * *$ & $0,26 * * *$ & $0.35 * * *$ & $0.39 * * *$ & $0,29 * * *$ & $0.34 * * *$ & $0.35 * * *$ & $0,25 * * *$ \\
\hline Combinação 3 & $0.18 * * *$ & $0.16^{* * *}$ & $0,08 * * *$ & $0.28 * * *$ & $0.18 * * *$ & $0,10 * * *$ & $0.24 * * *$ & $0.19 * * *$ & $0,14 * * *$ \\
\hline Combinação 4 & $0.26^{* * *}$ & $0.27 * * *$ & $0,25 * * *$ & $0.38 * * *$ & $0.39 * * *$ & $0,39 * * *$ & $0.36 * * *$ & $0.33 * * *$ & $0,30 * * *$ \\
\hline
\end{tabular}

Fonte: Os autores, a partir de Latin American Public Opinion Project (2010).

Nota: Combinação 1 = não experiência com corrupção e não participação política. Combinação 2 = experiência com corrupção e não participação política. Combinação $3=$ não experiência com corrupção e participação política. Combinação $4=$ experiência com corrupção e participação política. $*=$ p valor menor/igual a 0,$10 ; * *=p$ valor menor ou igual a 0,$05 ; * * *=p$ valor menor ou igual a 0,01 .

Tabela 14A - Predição de tolerância ao pagamento de propina de acordo com os perfis sociais (em probabilidade) - Ativismo comunitário

\begin{tabular}{|c|c|c|c|c|c|c|c|c|c|}
\hline & \multicolumn{3}{|c|}{ Chile e Uruguai } & \multicolumn{3}{|c|}{ Costa Rica e Nicarágua } & \multicolumn{3}{|c|}{ México e Peru } \\
\hline & 2006 & 2008 & 2010 & 2006 & 2008 & 2010 & 2006 & 2008 & 2010 \\
\hline Combinação 1 & $0.15^{* * *}$ & $0.13 * * *$ & $0,07 * * *$ & $0.20 * * *$ & $0.18 * * *$ & $0,10 * * *$ & $0.18 * * *$ & $0.18 * * *$ & $0,14 * * *$ \\
\hline Combinação 2 & $0.29 * * *$ & $0.23^{* * *}$ & $0,27 * * *$ & $0.37 * * *$ & $0.40^{* * *}$ & $0,31 * * *$ & $0.36^{* * *}$ & $0.38 * * *$ & $0,23 * * *$ \\
\hline Combinação 3 & $0.15 * * *$ & $0.15 * * *$ & $0,09 * * *$ & $0.24 * * *$ & $0.18 * * *$ & $0,11 * * *$ & $0.22 * * *$ & $0.19 * * *$ & $0,17 * * *$ \\
\hline Combinação 4 & $0.22 * * *$ & $0.42 * * *$ & $0,17 * *$ & $0.35 * * *$ & $0.38 * * *$ & $0,22 * * *$ & $0.31 * * *$ & $0.33 * * *$ & $0,29 * * *$ \\
\hline
\end{tabular}

Fonte: Os autores, a partir de Latin American Public Opinion Project (2010).

Nota: Combinação 1 = não experiência com corrupção e não participação política. Combinação 2 = experiência com corrupção e não participação política. Combinação 3 = não experiência com corrupção e participação política. Combinação $4=$ experiência com corrupção e participação política. $*=$ p valor menor/igual a 0,$10 ; * *=p$ valor menor ou igual a 0,$05 ; * * *=p$ valor menor ou igual a 0,01 .

Tabela 15A - Predição de tolerância ao pagamento de propina de acordo com os perfis sociais (em probabilidade) - Ativismo partidário e eleitoral

\begin{tabular}{|c|c|c|c|c|c|c|c|c|c|}
\hline & \multicolumn{3}{|c|}{ Chile e Uruguai } & \multicolumn{3}{|c|}{ Costa Rica e Nicarágua } & \multicolumn{3}{|c|}{ México e Peru } \\
\hline & 2006 & 2008 & 2010 & 2006 & 2008 & 2010 & 2006 & 2008 & 2010 \\
\hline Combinação 1 & $0.14 * * *$ & $0.14 * * *$ & $0,07 * * *$ & $0.20 * * *$ & $0.16 * * *$ & $0,09 * * *$ & $0.19 * * *$ & $0.17 * * *$ & $0,14 * * *$ \\
\hline Combinação 2 & $0.33 * * *$ & $0.27 * * *$ & $0,25 * * *$ & $0.32 * * *$ & $0.38 * * *$ & $0,30 * * *$ & $0.36 * * *$ & $0.34 * * *$ & $0,24 * * *$ \\
\hline Combinação 3 & $0.16 * * *$ & $0.13 * * *$ & $0,08 * * *$ & $0.25 * * *$ & $0.20 * * *$ & $0,12 * * *$ & $0.23 * * *$ & $0.20 * * *$ & $0,18 * * *$ \\
\hline Combinação 4 & $0.18 * * *$ & $0.23 * * *$ & $0,27 * * *$ & $0.39 * * *$ & $0.41 * * *$ & $0,31 * * *$ & $0.32 * * *$ & $0.35 * * *$ & $0,31 * * *$ \\
\hline
\end{tabular}

Fonte: Os autores, a partir de Latin American Public Opinion Project (2010).

Nota: Combinação 1 = não experiência com corrupção e não participação política. Combinação 2 = experiência com corrupção e não participação política. Combinação 3 = não experiência com corrupção e participação política. Combinação $4=$ experiência com corrupção e participação política. $*$ = p valor menor/igual a 0,$10 ; * *=p$ valor menor ou igual a 0,$05 ; * * *=p$ valor menor ou igual a 0,01 . 
Tabela 16A - Predição de tolerância ao pagamento de propina de acordo com os perfis sociais (em probabilidade) - Ativismo de protesto

\begin{tabular}{|c|c|c|c|c|c|c|c|c|c|}
\hline & \multicolumn{3}{|c|}{ Chile e Uruguai } & \multicolumn{3}{|c|}{ Costa Rica e Nicarágua } & \multicolumn{3}{|c|}{ México e Peru } \\
\hline & 2006 & 2008 & 2010 & 2006 & 2008 & 2010 & 2006 & 2008 & 2010 \\
\hline Combinação 1 & $0.16^{* * *}$ & - & $0,07 * * *$ & $0.22 * * *$ & - & $0,10 * * *$ & $0.19 * * *$ & - & $0,15^{* * *}$ \\
\hline Combinação 2 & $0.23 * * *$ & - & $0,23 * * *$ & $0.38 * * *$ & - & $0,31 * * *$ & $0.35 * * *$ & - & $0,26 * * *$ \\
\hline Combinação 3 & $0.12 * * *$ & - & $0,07 * * *$ & $0.24 * * *$ & - & $0,12 * * *$ & $0.24 * * *$ & - & $0,18 * * *$ \\
\hline Combinação 4 & $0.30 * * *$ & - & $0,41 * * *$ & $0.31 * * *$ & - & $0,26 * * *$ & $0.31 * * *$ & - & $0,29 * * *$ \\
\hline
\end{tabular}

Fonte: Os autores, a partir de Latin American Public Opinion Project (2010).

Nota: Combinação 1 = não experiência com corrupção e não participação política. Combinação 2 = experiência com corrupção e não participação política. Combinação 3 = não experiência com corrupção e participação política. Combinação $4=$ experiência com corrupção e participação política. $*=$ p valor menor/igual a 0,$10 ; * *=p$ valor menor ou igual a 0,$05 ; * * *=p$ valor menor ou igual a 0,01 . 